IZA DP No. 9859

Corruption, Norm Violation and

Decay in Social Capital

Ritwik Banerjee

March 2016 


\title{
Corruption, Norm Violation and Decay in Social Capital
}

\author{
Ritwik Banerjee \\ Indian Institute of Management Calcutta \\ and IZA
}

Discussion Paper No. 9859

March 2016

\author{
IZA \\ P.O. Box 7240 \\ 53072 Bonn \\ Germany \\ Phone: +49-228-3894-0 \\ Fax: +49-228-3894-180 \\ E-mail: iza@iza.org
}

\begin{abstract}
Any opinions expressed here are those of the author(s) and not those of IZA. Research published in this series may include views on policy, but the institute itself takes no institutional policy positions. The IZA research network is committed to the IZA Guiding Principles of Research Integrity.

The Institute for the Study of Labor (IZA) in Bonn is a local and virtual international research center and a place of communication between science, politics and business. IZA is an independent nonprofit organization supported by Deutsche Post Foundation. The center is associated with the University of Bonn and offers a stimulating research environment through its international network, workshops and conferences, data service, project support, research visits and doctoral program. IZA engages in (i) original and internationally competitive research in all fields of labor economics, (ii) development of policy concepts, and (iii) dissemination of research results and concepts to the interested public.
\end{abstract}

IZA Discussion Papers often represent preliminary work and are circulated to encourage discussion. Citation of such a paper should account for its provisional character. A revised version may be available directly from the author. 
IZA Discussion Paper No. 9859

March 2016

\section{ABSTRACT}

\section{Corruption, Norm Violation and Decay in Social Capital}

The paper studies the link between corruption and social capital (measured as trust), using data from a lab experiment. Subjects play either a harassment bribery game or a strategically identical but differently framed ultimatum game, followed by a trust game. In a second experiment, we elicit social appropriateness norm of actions in the bribery game and the ultimatum game treatments. Our experimental design allows us to examine whether subjects, who have been asked to pay a bribe, are less likely to trust than those in an isomorphic role in the ultimatum game. We also uncover the underlying mechanism behind any such behavioral spillover. Results suggest that a) there is a negative spillover effect of corruption on trust and the effect increases with decrease in social appropriateness norm of the bribe demand; b) lower trust in the bribery game treatment is explained by lower expected return on trust; c) surprisingly, for both the bribery and the ultimatum game treatments, social appropriateness norm violation engenders the decay in trust through its adverse effect on belief about trustworthiness.

JEL Classification: C91, C92, D03

Keywords: corruption, social capital, social norm, trust games

Corresponding author:

Ritwik Banerjee

IIM Calcutta

Diamond Harbour Road, Joka

Kolkata, West Bengal

India

E-mail: ritwikbanerjee@iimcal.ac.in 
"I am affected, not because you have deceived me, but because I can no longer believe in you."

- Friedrich Nietzsche, Beyond Good and Evil, 1886.

\section{Introduction}

Social capital, which comprises of commonly held values such as trust, trustworthiness and cooperative norms, is increasingly seen today as an important component of a successful economic environment. Given that social capital helps circumvent the necessity for expensive complete contracts and thereby decreases the costs of enforcing contracts (North, 1990; Williamson, 1985; Sobel, 2002), it is not surprising that it has been found to have a positive instrumental role in a wide range of economic activities: from economic growth (Knack and Keefer, 1997) to financial development (Guiso et al., 2004, 2008) and trade and investment (Guiso et al., 2009).

Studies show that this vital ingredient of economic activity is negatively associated with corruption in a cross country panel framework. Figure 1 documents this association in a dynamic panel of countries with trust data from World Value Survey (WVS) and corruption (perception) data from International Country Risk Guide (ICRG), aggregated over four WVS waves. It illustrates the stylized fact that not only is corruption and trust negatively related cross-sectionally, but the movement of most countries have followed a trajectory from high trust - low corruption to low trust - high corruption during the period, as is indicated by the arrows which point towards the South East for most countries.

This association has been studied primarily by political scientists and to a lesser extent by economists, however, the precise causal link and the mechanisms driving the association remain less known. Some have taken the view that low levels of trust in a society may engender and nurture corruption since people fail to develop cooperative ethos (LaPorta et al., 1997; Bjornskov, 2011; Seligson, 2002; Moreno, 2002). Others have argued that a lack of trust may diminish the sense of doing something wrong or "immoral", leading to a perception of high corruption in the society (Rotondi and Stanca, 2015), which in turn may lead to greater prevalence of corruption (Bardhan, 1997; Innes and Mitra, 2013). Corruption has also been viewed as a cause for the erosion of social capital (Anderson and Tverdova, 2003; Chang and Chu, 2006; DellaPorta, 2000). This view draws support from the impact of political scandals on trust (Bowler and Karp, 2004), and by relating confidence in institutions entrusted to control corruption to interpersonal trust (Rothstein and Stolle, 2002). Others still, have interpreted the relation as one of mutually reinforcing causality (see for instance Uslaner, 2002, Morris and Klesner, 2010). Despite the fact that the negative association between trust and corruption has been widely documented in a number of settings, the causal interpretation between the two is at best weak ${ }^{1}$.

\footnotetext{
${ }^{1}$ Potential simultaneity in the association between corruption and trust leads to endogeneity bias, which is difficult to overcome due to lack of suitable instruments and limited time varying and comparable cross-country data.
} 


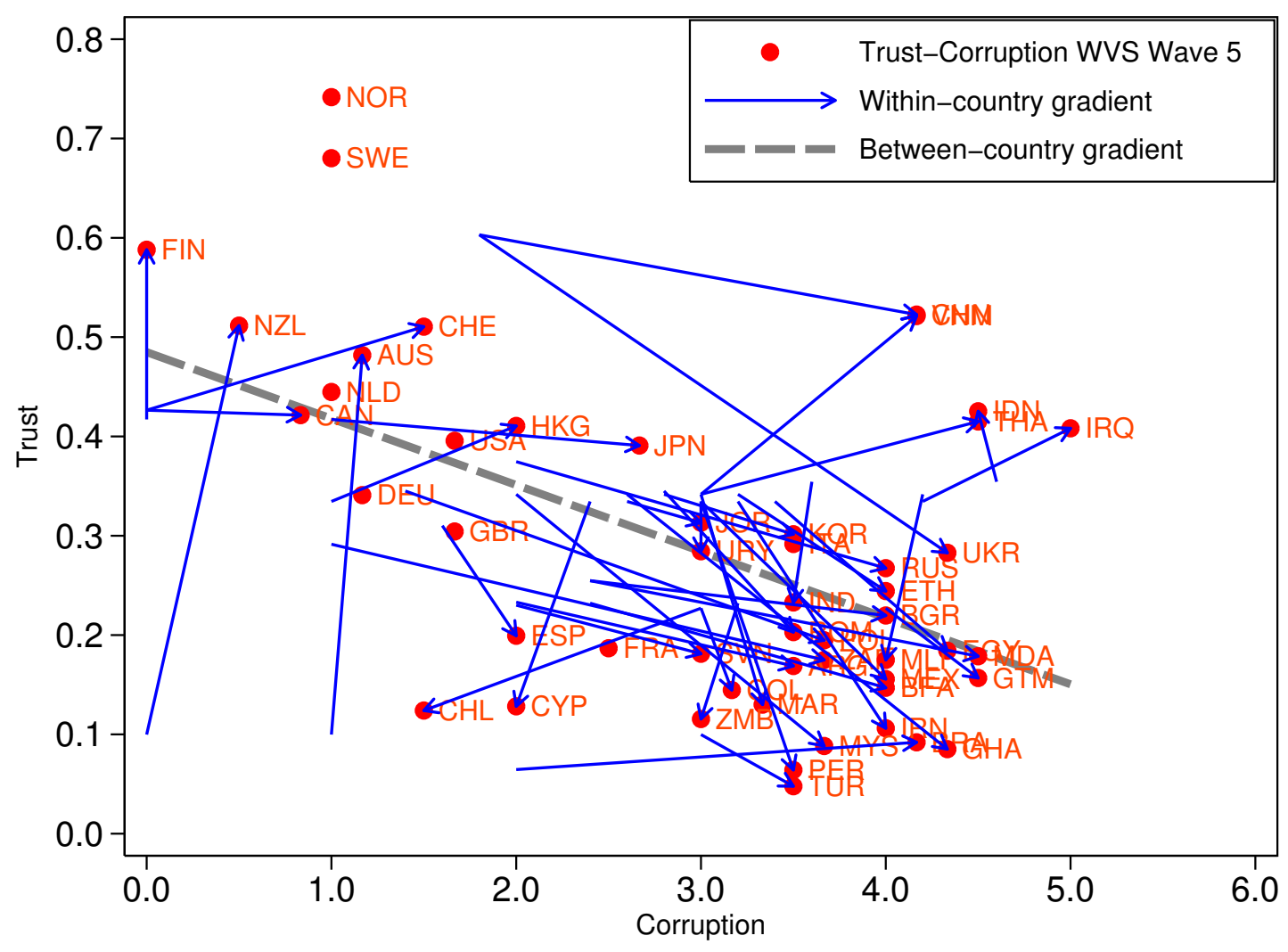

Figure 1: Within and between country gradient between trust and corruption

Note: Arrows indicate the movement of countries in the Trust-Corruption space from Wave 2 to Wave 5 in the World Value Survey. The dotted line shows the cross sectional gradient for Wave 5 in WVS (slope coefficient $=-0.07$, p-value $<0.01$ ). $68 \%$ of the 43 countries that we have data on, have arrows that point to the South East. The OLS regression coefficient, when change in corruption is regressed over change in trust, is -0.024 ( $p$-value $=0.36)$. These suggest that not only is the cross sectional correlation between corruption and trust negative, but over the period most countries have moved towards higher corruption and this movement has also been associated with lower trust. Data source: Corruption - International Country Risk Guide (ICRG); Trust - World Value Survey. Arrows in some data points are missing as these countries have only one data point each since WVS has brought more and more countries within its fold over time.

In this paper, we analyze one side of the potentially simultaneous relation and causally relate corruption to decay in trust using experimental data. Both corruption (or more generally unethical behavior) and trust originate from behavioral primitives and both have been extensively studied through lab based experimental methods in the past (for a review of experimental corruption games see Abbink and Serra (2012) and Serra and Wantchekon (2012)). First, we analyze if people exhibit less trust in a standard trust game after having played a bribery game than after having played a strategically identical but differently framed ultimatum game (for an analysis of the two frames see Banerjee (2016)). Second, we elicit social appropriateness norm of actions in the bribery and ultimatum game frame in order to identify the precise mechanism underlying any observed effect. Thus, our experimental design allows us to identify and estimate the causal link from corruption to trust, as measured through behavioral spillovers.

Behavioral spillover effect is defined as an effect which is observed only when an experimental 
game is played together with other games but not when played in isolation. Such effects, which are common in the experimental literature, have been found to enhance cooperation (Cason et al., 2012; Brandts and Cooper, 2006; Albert et al., 2007; Cason and Gangadharan, 2013), help attain a Pareto improving coordination equilibrium (Weber, 2006), induce rationality (Cherry et al., 2003; Cherry and Shogren, 2007) and even change actions when subjects hear about the actions of others in their group (Huck et al., 2011). Though some studies have inferred that higher cognitive load induced by greater outcome entropy, uncertainty and lesser path dependence induce positive behavior spillovers (Bednar et al., 2012; Cason et al., 2012), we know surprisingly little about the mechanisms behind negative behavioral spillovers. While studying the interplay between corruption and trust, our study also aims to fill this gap.

In the first experiment, we randomly assign people to either a real effort harassment bribery game or a strategically identical but differently framed ultimatum game ${ }^{2}$. After subjects have been through the experience of being in one of the frames and have known the outcomes, we measure their trust behavior in a standard trust game. In the bribery game, a "Citizen" performs a task and earns a prize if successful. However, a "Public Official" may demand a bribe in order to let the Citizen have her prize - the Citizen may subsequently accept or reject this bribe demand. In the strategically identical but differently framed ultimatum game treatment, "Participant A" (analogous to the Citizen) upon successfully completing the task - earns the right to go to the second stage of the game. At the second stage, "Participant B" (analogous to the Public Official) plays an ultimatum game, with the same stake size as the prize in the bribery game, and decides how much to share with Participant A, which the latter can accept or reject. In this way, not only do we cleanly identify the causal impact of corruption on trust but also answer whether lower trust in people is associated with greater unethical behavior.

Why do negative spillover effects originate in the first place? We hypothesize that in our setting negative spillover effects originate from violation of a certain commonly held moral code. In order to unravel this mechanism, in a second experiment, we elicit social appropriateness norm governing the bribery game and the ultimatum game using a coordination tool developed by Krupka and Weber (2012).

First, our results from the first experiment confirm that the two frames trigger different behavioral responses - in particular, the bribery frame successfully imposes the intended frame of immorality. It is indeed the case that the two frames are governed by different social norms and this partly explains the difference in actual behavior. Second, Citizens trust less than Participant As and the baseline subjects in the trust game but we find no difference in trustworthiness among

\footnotetext{
${ }^{2}$ Harassment bribery is a form of bribery where a Public Official asks for a bribe from a Citizen who is entitled to a service that the official is obligated to provide. Petty bribery of this nature is very common in developing countries where Citizens, despite being entitled to government services (e.g. passport, driver's license), have to pay a bribe in order to obtain them or avoid inordinate procedural delays. Harassment bribery has been studied through experimental games in the past by Banerjee (2016) and Abbink et al. (2014).
} 
them $^{3}$. Third, the expectations of the Citizens about the trustworthiness of the matched partner, is lower when compared to that of the Participant As and baseline subjects. The negative shock to expectation is driven by the violation of social appropriateness norm governing bribery and explains part of the difference in trust behavior. Interestingly, there is no independent effect of the corruption frame on trust i.e. there is no mindset effect, but there is a mindset effect of corruption on expectations about trustworthiness. Hence, our findings suggest that norm violation and corruption mindset affect expectation about trustworthiness, which in turn leads to lower trust. Finally, we find a weak negative association between corruption and trust behavior among Public Officials.

Our contributions to the literature are the following. We provide a clean identification of the causal link that corruption leads to lower trust using an experimental approach and thereby contribute to a longstanding debate. In doing so, we pin down the precise behavioral mechanism through which corruption affects trust and show that the decline in the social capital in a corrupt environment has much to do with the violation of social appropriateness norms. The explanations offered in past studies shed little light in terms of how and why behavioral spillovers play out in real life. To the best of our knowledge, ours is the first study to show that social appropriateness norm violation, through its effect on belief about others' behavior, plays an important role in generating negative spillovers. With this, we identify one potential channel through which behavioral spillovers work in wider social contexts and particularly in experimental games - namely that of social norm violation. Besides, we also contribute to the framing literature and show that the framing effect may partly be explained by the social appropriateness norms governing the frames.

The rest of the paper is organized as follows: Section 2 lays out the experimental design and briefly sketches the important survey questions. Section 3 presents the broad results and the mechanisms behind the results and Section 4 discusses the results and offers the concluding remarks.

\section{Experimental Design}

A simple way to examine the effect of corrupt transaction on trust is to compare the trust behavior of victims in a corruption game with that of subjects who do not participate in the corruption game (i.e. baseline treatment). However, such an exercise may bias the true effects of corruption on trust because income effects may arise from potential earnings. So we design a Bribery Game (BG) and develop a strategically identical but differently framed counterfactual of the bribery game, namely, the Ultimatum Game (UG). The two frames differ in terms of the language used - loaded (e.g. Citizen, Public Official, bribe etc.) vs. neutral (e.g. Participant A, Participant B, transfer etc.), and also in terms of the sense of entitlement among the subjects. Banerjee (2016) shows that

\footnotetext{
${ }^{3}$ For completeness we conducted a standalone baseline trust game - it was not preceded by either the bribery or the ultimatum game.
} 
the difference in the behavior between the two frames comes from the change in entitlement and not change in the language. After having randomly treated subjects either through BG or UG in the first part, we let them play a modified version of the trust game (Berg et al., 1995) in the second and then observe the trust behavior. Any treatment effect in the trust behavior between BG and UG treatments may be attributed to corruption, provided a stranger matching protocol is followed. For completeness and also to account for the fact that there may be a spillover from the natural exposure to corruption in India to trust, we run a baseline trust game and compare it with the trust behavior in $\mathrm{BG}$ and $\mathrm{UG}$ treatments.

The design of the BG and UG treatment relies on the prior that any amount demanded of subjects in a bribery game may be considered unfair in the bribery game, but the same amount when retained in an ultimatum game may be considered fair. If so, the two frames are expected to trigger different emotional responses despite being strategically identical. We exploit this and analyze the impact of the treatments on trust behavior. In addition, we also compare the impact of trust in BG and $\mathrm{UG}$ with that of baseline level of trust. This constitutes the first experiment of our study - it is designed to capture whether demanding bribe has a negative behavioral spillover on trust.

In the second experiment we aim to measure the fairness or social appropriateness norms governing the two frames and examine if the assumptions about the treatment differences discussed above are indeed correct. Figure 2(c) gives an overview of the complete experimental design. 
Citizen performs a task,

needs to complete it in 10 minutes

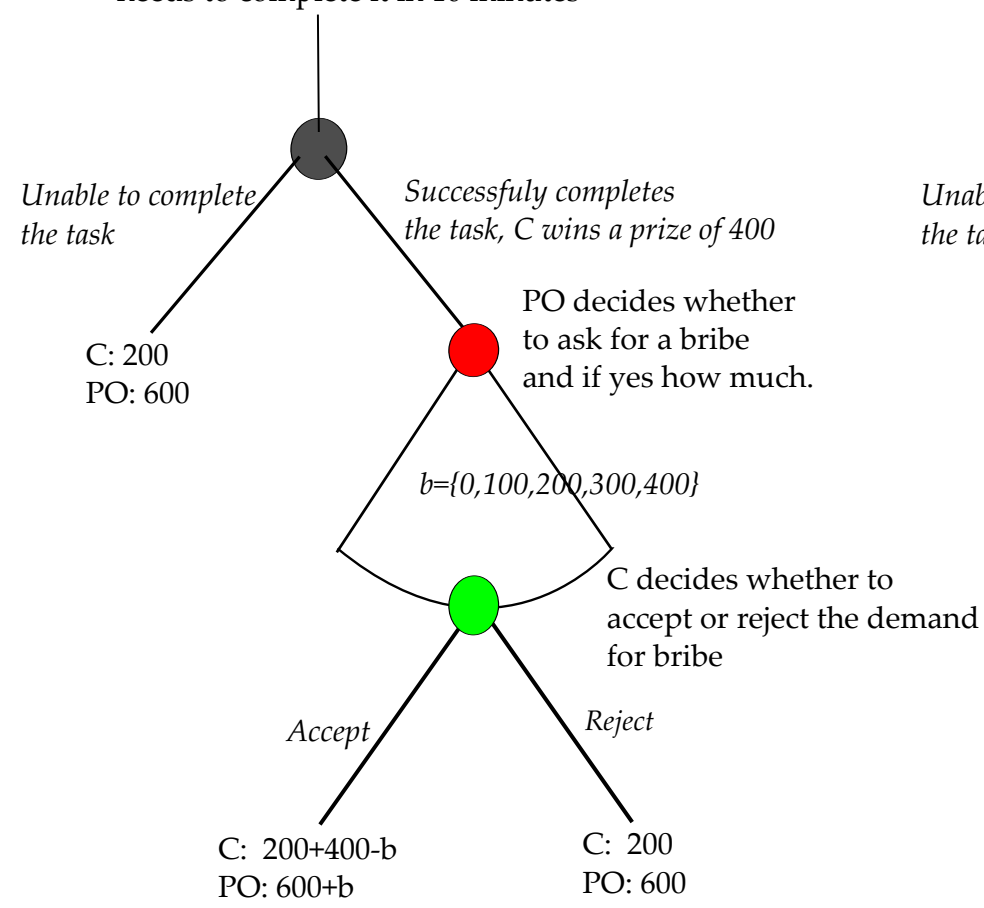

(a) Bribery Game
Participant A performs a task,

needs to complete it in 10 minutes

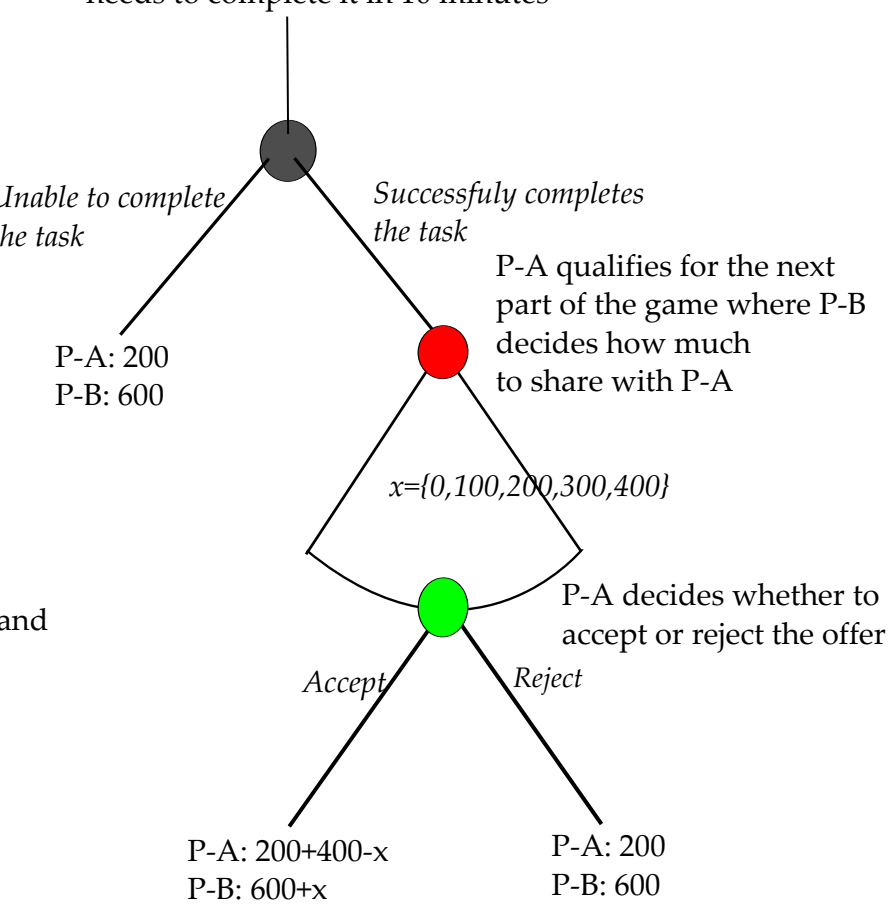

(b) Ultimatum Game

\section{Experiment 1}

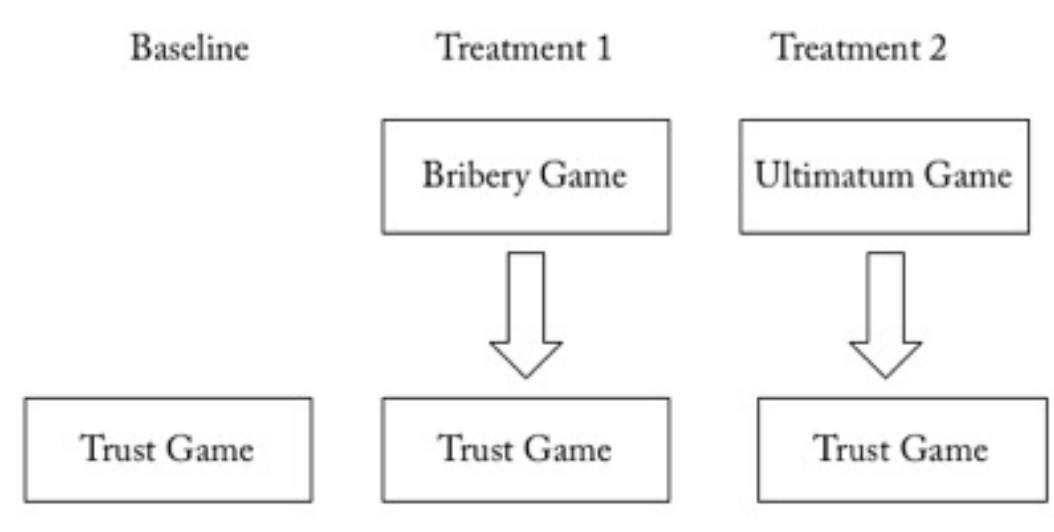

Experiment 2

\section{Social Appropriateness Norm Elicitation of Bribery Game and Ultimatum Game}

(c) Overview of experimental design

Figure 2: Bribery Game (BG), Ultimatum Game (UG) and Overview of experimental design 
The strategy of studying dynamic behavior after triggering a certain emotional response has been adopted by several studies in the past: for instance, Burnham et al. (2000) study the effect of framing the matched partner as a friend or foe, Drouvelis et al. (2010) prime cooperation in social dilemma games, Buser and Dreber (2013) examine the effect of competition on cooperation. Our experimental design follows a similar approach but with important differences as will be clear in the following sections.

\subsection{Bribery Game and Ultimatum Game}

Figure 2(a) describes the bribery game. A Citizen (C) has to complete a real effort task in ten minutes, following which she gets a prize winning code ${ }^{4}$. If she successfully completes the task and gets the prize winning code then she is entitled to a prize of 400 Mohars $(\mathbf{M} 400)^{5}$. Otherwise she earns only the participation fee of M200. However, even if the Citizen does get the prize winning code, a Public Official (PO) may demand a bribe of amount $b$ in order to let the Citizen have her entitled prize. Notice that the bribe of amount $b$ is an extract from the value of the Citizen's entitlement, which in this case is M400. So we assume that any bribe in excess of M400 will be rejected by a reasonable Citizen and let bribe demand take one of the following values - 0, 100, 200, 300, 400. When Citizen receives a bribe demand she has an opportunity to either accept it, thereby earning $\mathbf{M}(200+400-b)$, or reject it and earning only the participation fee of $\mathbf{M} 200$. This decision is elicited by strategy method. On the other hand, the Public Official gets a participation fee of M200 and a salary of M400 for the task of approving the Citizens. If his bribe demand is accepted by the Citizen, he earns $\mathbf{M}(200+400+b)$, else M600 only.

Note the following features about this bribery game. One, the minimum earning of the Public Official always exceeds that of the Citizen and hence bribery decisions cannot be interpreted by alternative explanations such as inequity aversion. Two, this one shot bribery game mimics the natural situation where a briber and a bribee meet only once. Three, the real effort task for the Citizen is calibrated in a way such that she is more likely to successfully complete the task and get the prize winning code. At the same time it is crucial for her to perform the task in order to induce in her a sense of entitlement and hence a sense of harassment if a bribe is demanded. It turned out that in our case all the subjects were able to complete the task and get the prize winning code. Finally, the bribery game discussed here abstracts away from many of the standard features of past corruption games in the literature, e.g. punishment and monitoring, social inefficiencies, third party

\footnotetext{
${ }^{4}$ We introduce a computer based task where Citizens have to count the number of occurrences of the letter "A" in five different panels, each with a random sequence of letters A, B, C, D, E. The panels appear one after the other and a subject is unable to proceed to the subsequent panel unless she correctly counts the number of As in the current one. They have ten minutes within which they are required to find the prize winning code, which is mentioned at the end of the fifth panel. The task is designed in such a way that a Public Official does not need to grade the answers of the Citizen but is still able to figure out whether she has been able to complete the task or not by looking at the prize winning code in her response sheet.

${ }^{5}$ Mohar (or gold coin) - the experimental currency unit in our set-up, was used as currency in medieval India.
} 
externalities etc. Thus, the only cost of engaging in corruption here is a moral one. Introduction of any of these features in our setup makes no difference to the underlying strategic or psychological elements in the game. Banerjee (2016) discusses the interpretation of bribery in this simple set-up and gives evidence that subjects do make immoral decisions when they demand a bribe.

The ultimatum game treatment, described in Figure 2(b), is isomorphic to the bribery game treatment described above, but with two main differences. One, it uses a neutral language frame by assigning roles as "Participant A" and "Participant B" instead of "Public Official" and "Citizen" and by using words such as "transfer" instead of "bribe". Two, while Citizens in the bribery game, upon successfully completing the task, were entitled to a prize, the Participant A (P-A henceforth) in this frame only qualifies to the second stage of the game where Participant B (P-B henceforth) plays an ultimatum game with her. Unlike in the bribery game, here the M400 endowment is with $\mathrm{P}-\mathrm{B}$ and this feature induces a change in the sense of entitlement between the two treatments. Thus, in the second stage $\mathrm{P}-\mathrm{B}$ decides to keep $\mathbf{M} x$ with himself and offers $\mathbf{M} 400-x$ to $\mathrm{P}-\mathrm{A}$, which P-A can either accept or reject. We implement a strategy method to elicit P-A's acceptance decision. If P-A accepts (rejects) the offer then she earns M200+400-x (M200) while P-B earns $\mathbf{M} 200+400+x$ (M600). The sub-game perfect equilibrium in UG (BG) is Participant A (Public Official) retains (demands) M400 and Participant B (Citizen) accepts it. Thus, the ultimatum game is designed to provide a strategically equivalent counterfactual to the bribery game but it evokes different psychological response due to the difference in the sense of entitlement.

\subsection{Trust Game}

The baseline trust game we implemented is a variant of the standard trust game where a sender is matched to a receiver. The sender is endowed with $\mathbf{M} 400$. He can then decide how much to send, $t \in\{0,50,100, \ldots 400\}$, to a receiver. Any amount sent is then multiplied by 3 . The receiver then decides how much to return, $w \in\{0,50,100, \ldots 3 t\}$, to the sender. As a result, the payoff of a sender equals $\mathbf{M}(400-t+w)$ whereas that of the receiver equals $\mathbf{M}(3 t-w)$. The predominant interpretation in the literature is that $t$ is a measure of trust, while $w$ is a measure of trustworthiness. While in the BG/UG treatment, the trust game is preceded by either the BG or the UG treatment, respectively, in the baseline treatment it is preceded by neither. We followed a stranger matching protocol such that partners in the trust game are different from those in $\mathrm{BG} / \mathrm{UG}^{6}$.

Subjects make their decisions both as a sender and a receiver in a strategy elicitation method and role uncertainty is enforced ${ }^{7}$. In the first decision, subjects play as a sender and they decide

\footnotetext{
${ }^{6}$ Behavioral spillovers have been found to be stronger when games are played with the same subjects than when they are played with different subjects (Cason et al., 2012). Our stranger matching protocol ensures that we do not pick up a trivial effect where a sender, after being a victim of a bribe demand, sends a lower amount (i.e. shows less trust) to the corrupt person she is matched with.

${ }^{7}$ There has been some evidence that strategy method reveals lower level of trustworthiness(Casari and Cason, 2009). However, in an exhaustive metastudy comparing strategy elicitation method versus direct method, Brandts and Charness (2011) finds that there was not even one case where treatment effect was found in strategy elicitation
} 
how much of their initial endowment they are willing to send to the receiver. They choose any amount between M0 and M400 in multiples of fifty. In the second decision, they indicate how much they expect to be returned by their matched receiver for each possible amount sent. To motivate the subjects to report their beliefs accurately, we incentivize this question by paying an additional M100 if the response matches the actual return of the receiver for a randomly chosen amount sent. The subjects then take a third decision, where they play the role of a receiver. In this decision they indicate the amount they are willing to return to the sender for each possible amount which they may have received. Thus, we obtain their response both on and off the equilibrium path, enabling us to perform a richer sensitivity analysis. The earnings from this part are determined by randomly picking either the role of a sender or that of a receiver.

\subsection{Social Norm}

A second experiment is conducted to gather data on the social norm governing $\mathrm{BG}$, UG and the trust game, using a tool developed by Krupka and Weber (2012). A separate group of subjects report their subjective assessment of how morally appropriate or inappropriate most people find the actions in a particular situation to be. They are rewarded if their appropriateness ratings match those of most other people (mode) in the session. Since the reward is given if a rating matches the mode of the distribution of ratings, it helps elicit a second order belief about the shared societal (other subjects in the session) perceptions about what is morally the right thing to do. Following Krupka and Weber (2012), we interpret the average rating as the social norm governing the situation.

Subjects are shown either the Bribery Game or the Ultimatum Game. Having seen the situation, they rate each action for each role as one of the following - "very socially inappropriate", "socially inappropriate", "somewhat socially inappropriate", "value neutral", "somewhat socially appropriate", "socially appropriate" and "very socially appropriate". The responses were later converted into numerical scores of $-3,-2,-1,0,+1,+2$ and +3 , respectively. We defined social norm governing a particular action in a given situation as the average social appropriateness rating for that action.

The protocol employed to elicit social norm closely follows the one laid down by Krupka and Weber (2012). Each subject is paid a participation fee of Rs. 110. In the BG situation subjects report their social appropriateness rating for the actions of the Public Official and that of the Citizen. A bribe amount is randomly chosen. The modal response of the appropriateness rating for the randomly selected amount is noted. If a subject's rating for the randomly selected category for either the Public Official or the Citizen is the same as the modal response, then she is paid double the participation fee, i.e. Rs. 220. The norm elicitation of UG and the trust game treatments

method but was not found in direct method. Given this finding and the fact that strategy elicitation method helps obtain an otherwise unobservable rich data and perform a robust sensitivity analysis, we decided to employ this method. We believe that the treatment effect we find would have been accentuated had we used a direct method. 
follow an identical protocol. To avoid contamination of elicited norm by subjects' actual choice and to avoid experimenter demand effect, we implement an entirely between subject design. A schematic overview of all the experiments are given in Figure 2(c).

\subsection{Hypotheses}

This subsection lays out the hypotheses that may be tested using the data from our experiment. For Experiment 1, we develop a theoretical framework, which closely mimics the experimental data generating process, in order to help us guide the data analysis. In this formal set up, presented in Appendix 1, we aim to unpack the mechanism which may potentially drive the spillover from corruption to trust. "Citizens" interact with "Public Officials" in order to obtain a certain public service in the first stage. Public Officials may be "honest" and "good" or "corrupt" and "bad". Whether a citizen meets an honest public official or a corrupt one is entirely fortuitous. Following their interactions with the public officials, citizens form beliefs about how trustworthy public officials are likely to be and then make a decision whether or not to trust a person in the second stage. The theoretical framework gives us some interesting predictions:

Prediction 1: If a citizen meets a corrupt (honest) public official in the first stage, then her belief about a matched person's trustworthiness decreases (increases).

Prediction 2: Meeting a corrupt (honest) public official in the first stage decreases (increases) the trust a citizen has for a matched person in the second stage.

Note that Prediction 1 and 2 are not merely statements about effects but a possible mechanism behind an affect. The data from our experiment allow us to test whether this mechanism is indeed at work. In order to identify whether the observed effect on trust is purely an income effect, we let subjects play the strategically identical but differently framed ultimatum game and examine whether identical amounts demanded in the bribery and ultimatum games have different effects on the trust game. Intuitively, the reason why that might be the case is simple: one may think of Participant B's transfer in the Ultimatum Game as an expression of trust or generosity, while in the Bribery Game the Citizen is a victim of an exploitative extraction ${ }^{8}$. Thus, this discussion along with the theoretical predictions presented above suggest that the two games will have different effects on trust and beliefs about how trustworthy others are, in the following way:

Hypothesis 1: Average trust shown by Citizens in the Bribery Game treatment is lower than that by Participant As in the the Ultimatum Game treatment.

Hypothesis 2: Conditional on facing a bribe demand, the average belief in matched partner's trustworthiness is lower among Citizens in Bribery Game treatment than among Public Officials in Ultimatum Game treatment. The distribution of beliefs about how trustworthy others are, are different across the two treatments.

\footnotetext{
${ }^{8} \mathrm{I}$ thank a referee for suggesting this interpretation.
} 
Hypothesis 3: A social appropriateness norm may be assigned to any demand in the Bribery Game or Ultimatum Game. A violation of social appropriateness norm in either game leads to a decrease in the belief about how trustworthy others are. This in turn leads to a fall in the level of trust.

The main aim of this paper is to examine whether a bribe demand leads to a decrease in trust. However, our experimental setup allows us to examine two other interesting and related hypotheses as well. One: besides trust, trustworthiness too falls under the broad category of social capital. Can bribe demand have a spillover effect on trustworthiness too? Notice that trustworthiness is a conditional reciprocal decision i.e. trustworthiness decisions are made for a certain level of trust. Thus, there is no apriori reason why trustworthiness decisions should be affected by prior experience, fair or unfair. Two: if fairness norm is indeed an important foundation on which our behavior is based, then fairness should transcend context i.e. people whose behavior is fair in one context should also behave in a fair manner in another. In our context, this reasoning implies that public officials who demand less bribe should trust more in the trust game. Therefore, we test two additional hypotheses:

Hypothesis 4: Amount demanded (or the corresponding social appropriateness norm) in Bribery Game or Ultimatum Game does not affect the trustworthiness behavior of Citizens or Participant As in the trust game.

Hypothesis 5: Bribe demand and trust are negatively correlated for public officials i.e. those who take socially appropriate decision in the Bribery Game also do so in the trust game.

Our experimental data allow us to test all the hypotheses stated above.

\subsection{Experiment Procedure}

The experiment was conducted with student subjects at a management institute in Delhi. A total of 298 students were recruited and each subject participated in only one role of one treatment, out of which 182 participated in the BG and UG treatment, 36 participated in the baseline trust game and 80 in the social norm elicitation of BG and UG (40 in each). Sessions were randomly assigned UG and BG treatments and subjects were randomly assigned roles. The subjects were divided into two equal groups - each group was allocated a different room. The instructions for the respective roles were read out in English. Several examples were worked out and the earnings of both roles were calculated. The final earnings of the subjects were determined by randomly picking either BG/UG or the trust game. The sessions lasted for one and a half hours. At the end of the experiment participants exchanged their earnings for Rupees at the rate of 100 Mohars=Rs.50. The earnings ranged from Rs. 100 to Rs. 700 with an average of Rs. 252 ( 10 USD in PPP terms). 


\section{Results}

\subsection{Spillovers from Corruption to Trust and Trustworthiness}

\subsubsection{Trust}

We had 45 and 46 pairs of subjects in UG and BG treatments, respectively, all of whom successfully completed the task. Since our focus is on the effect of being at the receiving end of corruption, we will restrict our attention to the trust behavior of Citizens in BG, Participant As in UG and subjects of the baseline trust game in the following discussion, unless otherwise stated.

We find significant differences in the way people perceive BG and UG frames. A KolmogorovSmirnov test rejects the null hypothesis that the distributions of the amount demanded are equal across both the treatments $(p$-value $=0.03)$. Not only do we find that $19 \%$ of the subjects do not demand a bribe in the BG treatment as opposed to none in UG ( $\chi^{2}$ test, $p$-value $=0.00$ ), the mean amount demanded is M182.6 in BG and M268.9 in UG ( $t$-test, $p$-value $<0.001)^{9}$. For the sample where an amount was demanded, we reject the hypothesis that demand is equal in BG and UG $(t$-test, $p$-value $=0.02)$. Furthermore, as Figure 3a shows, the percentage of Citizens who reject a demand is always greater than that of P-As, indicating that an amount demanded is considered unfair in the BG than in the UG. For the statistical differences see Table 1. The results clearly show that the two frames, though strategically identical, have triggered different behavioral responses not only among Public Officials/Participant Bs but also among Citizens/Participant As.

The two frames are also governed by different social appropriateness norm - this is evident from the left panel of Figure 3b, which plots the social appropriateness norm for the two frames. Social appropriateness of demand decreases with an increase in the amount in BG, but follows an inverted $\mathrm{V}$ with equal split being most socially appropriate in UG. This goes some distance in explaining an observation made by Güth and Kocher (2014) that "the modal split is an extremely robust phenomenon" in thirty years of Ultimatum Game play. For full distribution of the ratings see Table 7 in Appendix 2.

Figure 4 lays out the distribution of the levels of trust between BG and UG and compares the mean trust levels (amount shared as a sender in the trust game) of the Citizens with that of the Participant As. A chi-square test rejects the null hypothesis that both distributions are equal $(p \text {-value }=0.04)^{10}$. The full sample mean amount sent by the Citizens in the role of sender is M205.4 while that of the Participant As is M261.1. Table 1 shows that the difference is statistically significant $(t$-test, $p$-value $=0.04$ ). The difference between the amount sent remains

\footnotetext{
${ }^{9}$ The proportion of subjects who behave in a self regarding and dishonest manner is high even when compared to similar studies in India. A recent literature suggests that subjects with business, economics or finance backgrounds are more likely to be dishonest than others (Cohn et al., 2014; López-Pérez and Spiegelman, 2012; Dasgupta and Menon, 2011). The fact that our subject pool is also drawn from business students may partly explain why so many subjects demand bribe.

${ }^{10} \mathrm{~A}$ Kolmogorov-Smirnov test however fails to reject the null of equality of distributions in this case.
} 

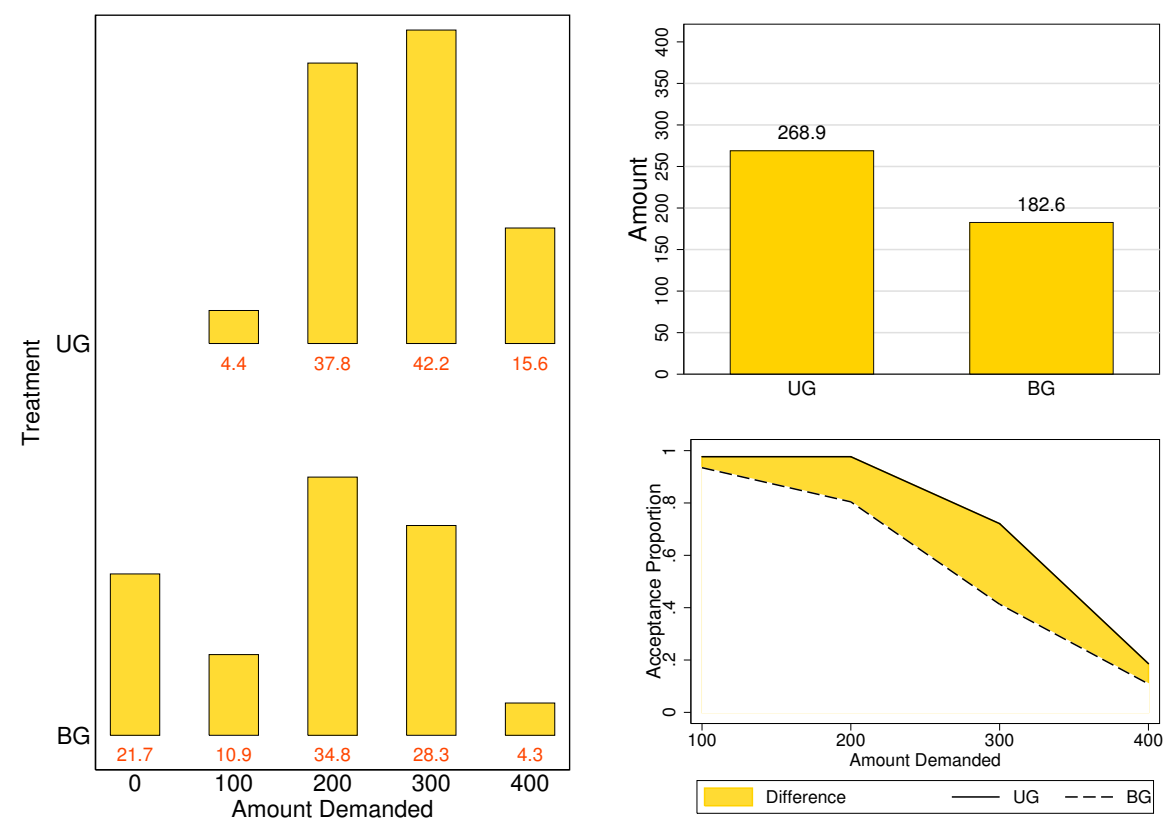

(a) Amount demanded and Acceptance decision

The figure on the left compares the distribution of amount demanded in BG and UG while that on the top right compares the average demand in BG with average demand in UG for the full sample. The bottom right figure compares the acceptance rates of the Citizens and Participant As for the different amounts, the shaded area being the difference between them.
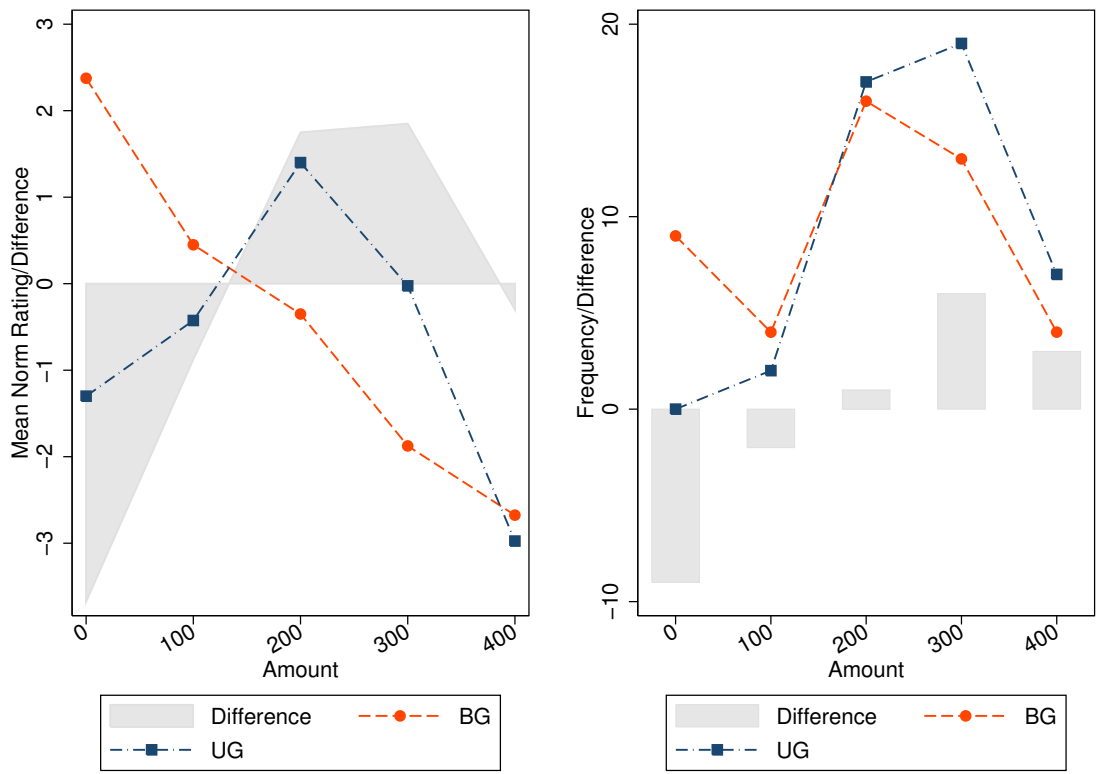

(b) Social Norm and Actual Behavior

The figure on the left compares the social norm of demand in BG and UG and the shaded region marks the difference. The figure on the right plots the number of subjects who demanded a particular amount in the BG/UG treatment. Clearly, the pattern of difference in social norm closely follows the difference in actual behavior.

Figure 3: Bribery and Ultimatum Game 
statistically significant even when conditioned on those who decide to send a positive amount $(t$-test, $p$-value $=0.08)$. These results indicate that Citizens, who are at the receiving end of bribery, tend to trust less than Participant As, who play a strategically identical but differently framed role in the Ultimatum Game. Clearly, the fact that Participant A in the Ultimatum Game is in some sense the beneficiary of trust or generosity and Citizen in the Bribery Game is a victim of exploitation seems to drive behavior in the subsequent trust game. This supports Hypothesis 1.

Interestingly, it is the trust behavior in the BG treatment, and not in the UG treatment, which differs from the baseline trust distribution: both distribution and mean trust differs between BG and baseline treatments $(\mathrm{KS}, p$ - value $=0.10$ and $t$-test, $p$-value $=0.06$ ) but not between $\mathrm{UG}$ and baseline trust treatments $(\mathrm{KS}, p$ - value $=0.80$ and $t$-test, $p$ - value $=0.88)$. However, the subsequent discussion mainly focuses on the comparison between the trust behavior of Participant As and Citizens.
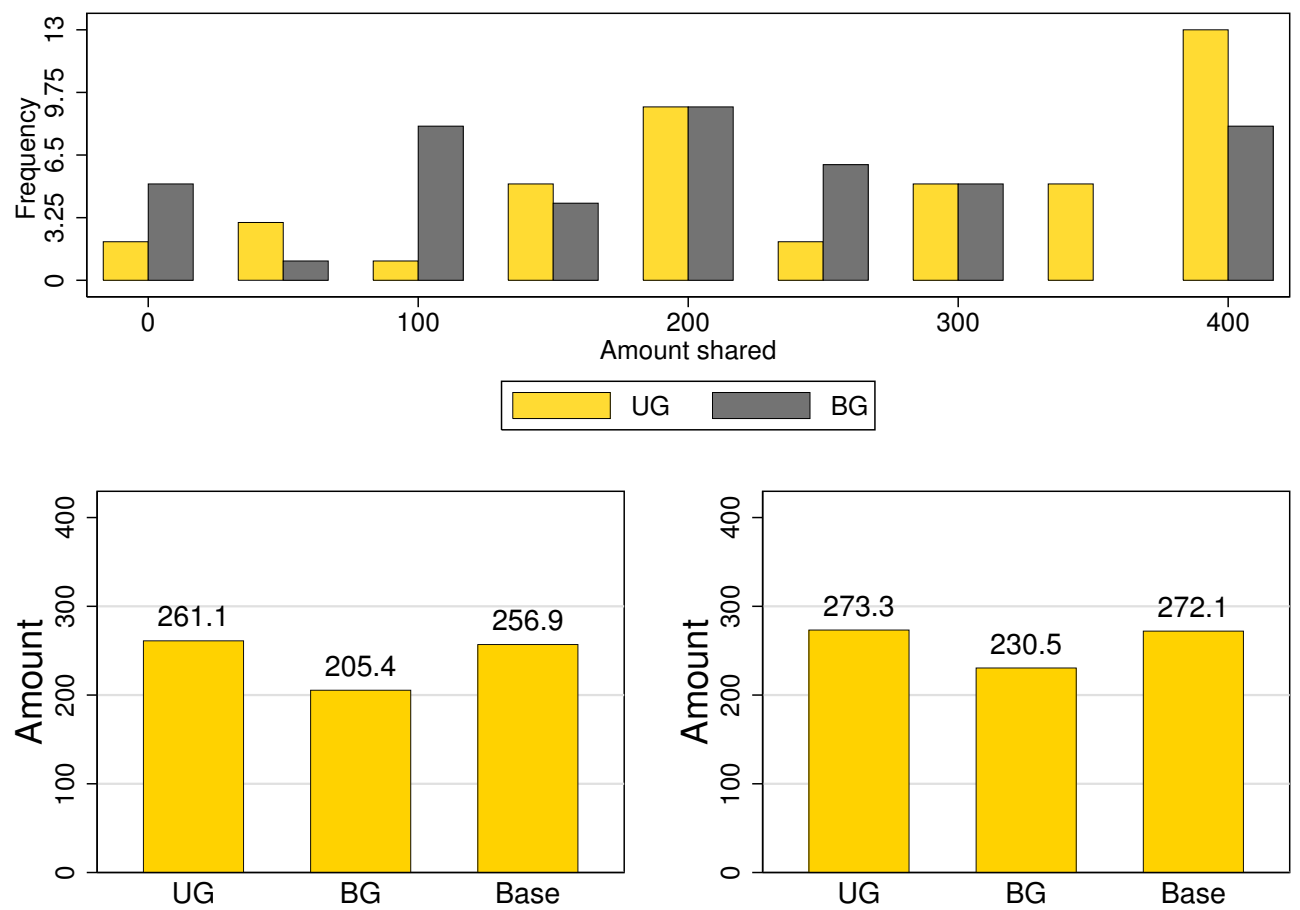

Figure 4: Trust behavior in UG, BG and baseline.

The figure on the top lays out the distributions of the amount shared by a Citizen/Participant A in the trust game. The bottom left and bottom right figures compare the mean amount shared by Citizens in BG, Participant As in UG and baseline subjects for the full sample (including those who did not share anything) and restricted sample (excluding those who did not share anything), respectively.

The difference in the trusting behavior between the BG and the UG treatment persists after controlling for the amount demanded and beliefs about others' trustworthiness, measured as expected return on trust (ERoT), as shown in col (1) in Table 2. Notice that since subjects hold beliefs about others' trustworthiness for every possible level of trust, beliefs across different trust levels cannot be aggregated unless they are normalized. ERoT, defined as (Expected Return for atrustlevel- 
Trustlevel)/Trustlevel, is one way of normalizing the conditional beliefs. Col (2) - (5) control for the social appropriateness norm of the amount demanded from the Citizens instead of the amount themselves, besides other variables such as ERoT, demographics and preferences. Interestingly, the treatment effect disappears in these specifications with social norm as a covariate, but the social norm coefficient remains positive and statistically significant. The coefficients suggest that for each unit increase in average social appropriateness rating of amount demanded, the average trust level increases by M18 to M19.5, depending on the specification. This means that it is not the treatment per se, but the social appropriateness (or inappropriateness) of the decisions that generates the treatment effects. ERoT has a positive statistically and economically significant coefficient, meaning that an increase in expected return increases trust levels. Except the negative coefficient of female, none of the demographic variables explain the trust levels. The fact that females trust less in our sample than males is consistent with evidence from past studies (Buchan et al., 2008; Croson and Gneezy, 2009). Col (5) of Table 2 reports the ordered probit estimates of the amount shared - the direction of the results are consistent with the ordinary least square estimates $^{11}$.

Table 1: Mean Differences in BG/UG and Trust Game

\begin{tabular}{ccccc}
\hline Variables $^{a}$ & BG & UG & Difference & $p$-value \\
\hline \% who asked for bribe/ultim & 81 & 100 & 19 & $<0.01$ \\
Amount (Full Sample) & 182.6 & 268.8 & 71.1 & $<0.01$ \\
Amount (Restricted Sample) & 245.9 & 268.8 & 22.9 & 0.02 \\
\% who accepted when amount=100 & 93.5 & 97.8 & 4.3 & 0.31 \\
\% who accepted when amount=200 & 80.4 & 97.8 & 17.4 & $<0.01$ \\
\% who accepted when amount=300 & 41.3 & 73.3 & 32.0 & $<0.01$ \\
\% who accepted when amount=400 & 10.8 & 17.8 & 7 & 0.34 \\
\% who decided to trust & 89.1 & 95.6 & 6.5 & 0.25 \\
Trust Amount (Full Sample) & 205.4 & 261.1 & 55.7 & 0.04 \\
Trust Amount (Restricted Sample) & 230.5 & 273.3 & 42.8 & 0.08 \\
\hline
\end{tabular}

${ }^{a}$ The restricted sample consists of only those who demanded an amount or those who chose to trust.

${ }^{b}$ For comparing proportions in the table, $p$-values from $\chi^{2}$ test of equality of proportions are reported. For comparison of sample mean, $p$-values from $t$-test are reported.

\subsubsection{Mechanism}

What is the precise mechanism through which norm violation, beliefs and trust affect each other? To answer this, we will look at the predictions from the theoretical framework presented in Appendix

\footnotetext{
${ }^{11}$ Since trust or the amount sent by the sender in our case - $I$, is an ordinal and discrete variable, one may argue that the actual propensity to trust $I^{*}$ is latent and thus unobservable. The mapping between $I$ and $I^{*}$ is given by $I_{i}^{*}=\boldsymbol{x}_{i}^{\prime} \beta+\varepsilon_{i}$ and $I_{i}=t$ if $s_{t-1}<I^{*} \leq s_{t}, t=0, \ldots, T$. $\beta$ - the parameter of interest can then be obtained by an ordered probit estimate.
} 
1 and some empirical facts. First, we analyze the data on expectations or beliefs about others' trustworthiness (measured by Expected Return on Trust). Figure 5(a) plots the average expected return on trust (ERoT) for each possible trust levels using the full strategy vector data. It shows that the expected return is significantly less for the Citizens in BG than the Participant As in UG, especially for lower levels of trust. This implies that Citizens have suffered a negative shock to their expectations about trustworthiness of their matched partners, when compared to Participant A or baseline subjects. Average ERoT for all trust categories among Citizens in BG treatment is -0.10; this is significantly lower than that among Participant As in UG, which is 0.05 (t-test, $p$-value $=0.04)$. Clearly, our data supports Hypothesis 2. Figure 5(a) also shows that ERoT is largely negative, specially for lower levels of trust suggesting that subjects display low expectations (largely negative) about the trustworthiness when the full strategy vector is considered, though their expectations corresponding to their actual response is greater than zero and thus consistent (not reported).

Second, the average social norm of amount demanded in BG is -0.38 while that of amount demanded in UG is 0.04 (MW test, $p$-value=0.04). Figure 6 in Appendix 2 illustrates that there is relatively more mass on social inappropriateness for BG than UG. These two observations together suggest norm violation may have been the reason behind the negative belief shock which the citizens have experienced - a channel which we formally test later.

Interestingly, average ERoT, as reported by the Citizens, is negatively associated with the amount of bribe demanded from them in the BG treatment (correlation coefficient $=-0.001, p$-value $=$ 0.08). This supports Prediction 1 from our theory which states that a citizen's belief about matched partner's trustworthiness decreases if she meets a corrupt person. Furthermore, there is a negative statistically significant association between bribe amount and trust (correlation coefficient $=-0.29$, $p$-value $=0.05$ ), indicating that keeping the institution of Bribery Game fixed, higher bribe demand has an adverse effect on trust. The pattern substantiates Prediction 2 and is broadly consistent with the stylized fact we observe in Figure 1. Cleary, our simple setup goes some distance in trying to understand the complex relation between corruption and trust. 


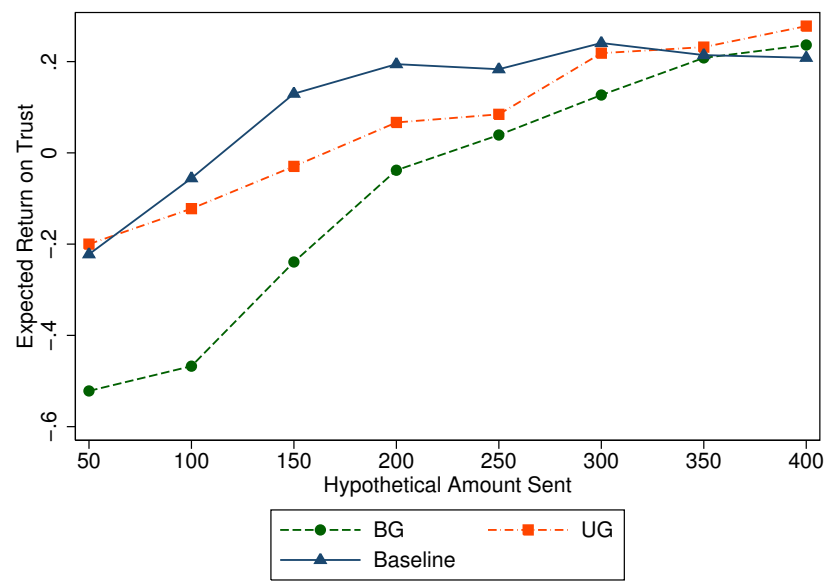

5(a) The panel plots the average Expected Return on Trust for full strategy vector data of subjects in baseline and those playing Citizen and Participant A in BG and UG, respectively.

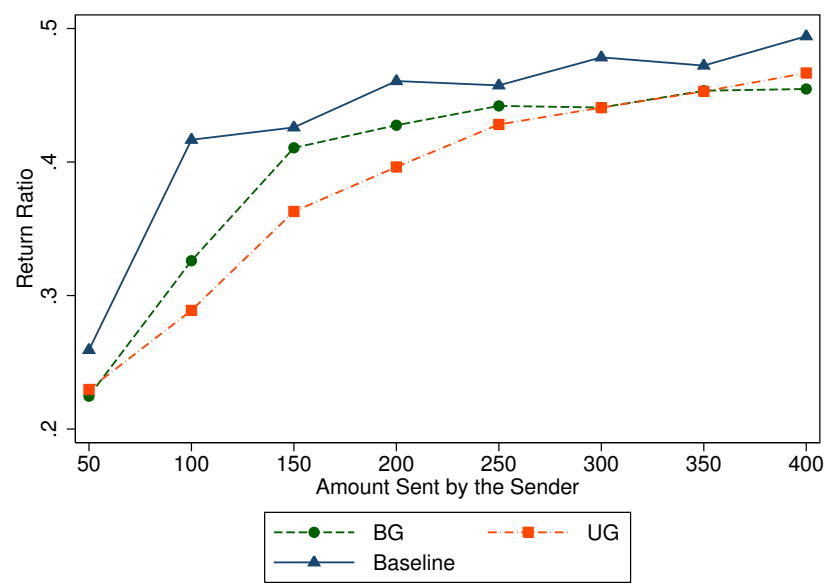

5(b) The panel plots the average Return Ratio (i.e. trustworthiness), for all possible bribe amounts, of subjects in baseline and those playing Citizen and Participant A in BG and UG, respectively.

Figure 5: Expected (5(a)) and Actual (5(b)) Return on Trust

The OLS estimates of col (2) - (4) and the ordered probit estimates of col (5) in Table 2 show that the Bribery Game frame by itself does not lead to the treatment effect, and thus the treatment effect is most likely not generated through priming or mindset effects. However, the positive, statistically and economically significant coefficients corresponding to the social norm suggest that if a Citizen/Participant A faces a socially inappropriate demand then she trusts less. Now, consider this with the finding that average social appropriateness measure of amount demanded in $\mathrm{BG}$, -0.38 , is significantly lower than that in $\mathrm{UG}, 0.04$ (MW test, $p$-value=0.04). Together they imply that Citizens have faced more socially inappropriate demands on average than Participant As and this in turn has generated lower trust.

Besides social norm, average ERoT turns out to be positive and statistically significant when it is used as a covariate in the regression of trust (col (2) - (5) in Table 2) meaning that the expectation of trustworthiness of the matched partner predicts trust. However, it is important to note that these specifications yield biased estimates since the ERoT is endogenously determined. Not only is 
this apparent conceptually from Equation (7) and (8) in Appendix 1, but also empirically from Figure 5(a) where ERoT is seen to systematically vary with treatment ${ }^{12}$. Thus, we estimate an empirical specification where the treatment dummy and social appropriateness norm can potentially affect beliefs about trustworthiness in the first stage while in the second stage trust decisions are influenced by predicted beliefs, demographic characteristics and preferences. Hence, the structural equations in terms of the experimental data are given by

$$
\begin{gathered}
\text { TRUST }=\beta_{0}+\beta_{1} E(E R o T \mid B G, N O R M)+\beta_{\mathbf{2}} \mathbf{X}+\beta_{\lambda} \lambda+\beta_{\theta} \theta+\epsilon \\
E R O T=\gamma_{0}+\gamma_{1} B G+\gamma_{2} N O R M+\nu
\end{gathered}
$$

where TRUST is the trust decision of the sender, $\mathbf{X}$ is the set of exogenous characteristics of the subject, $\lambda$ and $\theta$ are the risk and pro-sociality parameter, $B G$ is the treatment dummy and $N O R M$ is the exogenously elicited appropriateness measure of the amount demanded from the subject. Note that we follow Dohmen et al. (2011), who find that the approach of asking people a survey question about their "willingness to take risks in general ... generates a useful all-round measure", to obtain the risk profile (proxy for $\lambda$ in Equation (1)) of the subjects. For altruistic preference, we ask subjects how much they are willing to share with a charity if they win a lottery of Rs. 1000 (proxy for $\theta$ in Equation (2)). The joint estimation of Equation (1) and (2) assumes that the social appropriateness of the amount demanded and the treatment dummy affects trust through the expected return on trust but not independently i.e. the exclusion restriction holds. Our parameters of interest are $\beta$ which is consistently and unbiasedly estimated using a 3SLS procedure.

Col (1) - (3) in Table 3 report the first and second stage results. Interestingly, the first stage results show that the treatment dummy has a negative and significant effect and social appropriateness norm a positive and significant effect on ERoT. The positive significant effect of social norm on beliefs shows that beliefs respond positively to a fair outcome, not necessarily a higher outcome. Thus, controlling for the unfairness embedded in the institutional setup of the bribery game, social appropriateness of an amount demanded increases belief about trustworthiness. Note from Figure $3 b$ that while a bribe amount and its fairness has a negative and monotonic relation, less UG-demand is not always considered fair - the peak of social appropriateness in UG is in fact at equal split. It turns out that neither beliefs nor actual trust behavior differs across UG and BG treatments for the most and least fair demand (not reported). Thus, it is the social appropriateness norm corresponding to the demand, and not the amount per se, which affects the beliefs and the subsequent trust decisions. Hence, whether or not social norm has been violated is

\footnotetext{
${ }^{12}$ Formally we test for endogeniety using a Durbin-Wu-Hausman test and this leads to a rejection of the null hypothesis that the mean ERoT is exogenous $(p$-value $=0.07)$.
} 
an important factor in the underlying model which predicts trust decisions.

The second stage results of col (1) and (2) show that the coefficient of ERoT is positive and significant at $10 \%$ level. The corresponding coefficient in col (3), which estimates the model with a range of control variables, is marginally insignificant with $p$-value $=0.10$. Thus, the estimation results reveal that the predicted ERoT has a positive effect on actual trust decisions. Therefore, results from the joint estimation of ERoT and trust confirm the following mechanism at work: the corruption frame decreases expectations of trustworthiness and the social appropriateness of amount demanded increases it. The expectations of trustworthiness in turn determine the actual trust decisions. Thus, the mechanism stated in our third hypothesis is supported by the data.

A caveat - predictions from the model assume trustworthiness and bribe demand behavior are negatively associated. Is this assumption consistent with the actual data? First, the correlation coefficient between bribe demand and average Return Ratio for PO in BG is indeed negative, -0.10 , but statistically insignificant $(p$-value $=0.50)$. The association is also negative (though statistically insignificant) with and without the standard set of controls used elsewhere in this paper (not reported). Second, the average Return Ratio of Public Officials with zero bribe demand is 0.46 and it is higher than those with non-zero bribe demand, 0.40. But the difference again is not statistically significant $(t$-test, $p$-value $=0.28)$. So there is some indication that unethical and trustworthiness behavior are negatively associated but it is not conclusive. However, note that it is not important that trustworthiness and corruption behavior should be negatively related in our data for our proposed mechanism to work. As long as Citizens believe that trustworthiness and corruption behavior are negatively related, the mechanism works - checking this is beyond the scope of our paper.

\subsection{Other Results}

\subsubsection{Trustworthiness behavior}

The trustworthiness data was obtained by the strategy method. To analyze this behavior, we convert the hypothetical amount returned by a receiver for every possible trust level to a Return Ratio (RR) where $R R=$ Amount Returned/Amount Received. Col (4) - (6) in Table 3 report the ordinary least square regression results of trustworthiness of the Citizens and Participant As - measured in terms of average Return Ratio. It turns out that there is no difference in trustworthiness between Citizens and Participant As. Also, neither the amount demanded nor the corresponding social appropriateness norm predict trustworthiness - thus affirming our Hypothesis 5. This is evident from the proximity of the BG and UG Return Ratio curves which are plotted in Figure 5(b) - for none of the trust categories, the difference in Return Ratio is statistically significant. The only variable which seems to capture trustworthiness is ERoT, indicating that a subject's expectation

about her matched partner's trustworthiness seems to predict her own trustworthiness behavior. It is difficult to say whether subjects form their expectations about others' trustworthiness from their 
own trustworthiness behavior or the other way round, but in a homogenous subject pool like ours, both mechanisms can potentially be at work.

Two things should be noted here. One, our result that bribe demand affects trust but not trustworthiness is related to a small literature which suggests that trust and trustworthiness are not determined by the same fundamentals i.e. one does not necessarily imply the other (Chaudhuri et al., 2003; Chaudhuri and Gangadharan, 2007). Two, we do observe the monotone concave shape of the return ratio curve found in past studies (Bellemare and Kroger, 2007).

\subsubsection{Correlation between trust and bribe demand}

In Table 4 we briefly look at the correlation between bribe demand and trust behavior of Public Officials. We find that trust is negatively associated with a demand for a bribe as indicated by col (1) and (2), though the strength of the association is weak. In col (3) - (4), we replace bribe demand with the social appropriateness norm corresponding to the bribe amount and find that the coefficient of social appropriateness measure is economically and statistically significant. This implies that Public Officials who took more socially appropriate actions in the bribery game also trusted more in the trust game - an affirmation of Hypothesis 6. Note that these results are behavioral correlates only, no causation is implied here.

\section{Discussion and Conclusion}

In real life people interact with each other strategically in many different settings. These interactions affect our priors which in turn influence our subsequent decisions. However, the majority of experimental research focuses on behavior in experimental games in isolation. To mimic some of the real life situations of interrelated behavioral effects, past studies have designed experiments that generate "behavioral spillover effects" (Knez and Camerer, 2000; Ahn et al., 2001; Cason et al., 2012). Such spillovers can help improve coordination or cooperation (Cason et al., 2012) or worsen them (Buser and Dreber, 2013). These effects are different from other related psychological concepts such as priming and pure mindset effects. While priming arises from very subtle interventions, which work even by simply reminding people of some priming elements, behavioral spillovers arise when there are real consequences in terms of monetary payoffs.

In this paper we provide evidence of negative spillover i.e. the effect of bribe extraction on trust. Subjects are randomized into either a harassment bribery game or a strategically identical but differently framed ultimatum game. Both treatments are followed by a trust game. Despite

being identical in strategic terms, the two games differ in terms of the language in which they are described and entitlements of the players. Thus, our experimental design is informed by some recent experimental evidences which show that entitlements anchor behavior by altering psychological reference point (Oxoby and Spraggon, 2008; Abeler et al., 2011). 
Both these differences induce different moral centers in the frames and consequently trigger different psychological responses. We show that people in the Bribery Game treatment trust less than those in the Ultimatum Game treatment - this provides a causal link that corruption leads to lower trust. Furthermore, we provide an insight into the mechanism behind the negative spillover effect. Our evidence suggests that a demand for bribe violates social appropriateness norm and norm violation in turn negatively affects belief about the matched partner's trustworthiness. Since actual trust behavior is partly shaped by the belief about how trustworthy a matched partner is, the negative belief shock triggers a decrease in the level of trust through a rightward shift in the prior about the prevalence of norm violators in the trust game. This mechanism indicates that subjects exhibit some kind of a generalized indirect negative reciprocity, when faced with norm violations. Interestingly this operates through a change in beliefs rather than preferences - a finding which is consistent with evidence on social framing effects from past studies (Ellingsen et al., 2012). However, this is a subject which needs further investigation - Gächter et al. (2013), for instance, finds that observed peer effect in their gift exchange game is explained by social preferences rather than norm induced beliefs.

A few important caveats must be placed at this point. First, behavioral spillovers, of the kind we study in this paper, are short lived in nature. The priors are more likely to go back to the steady state levels with time. However, we conjecture that repeated interactions in a corrupt environment may lead to a behavioral stationary state of low trust (see for instance Sah (2007)). Of course our experiment, being a one shot game, has no way of verifying this conjecture. Second, it may very well be the case that lack of trust also engenders unethical behavior. Our experiment cannot identify this aspect of the causality but it is a matter of interest for future research. Third, our proposed mechanism assumes that corruption behavior is negatively associated with trustworthiness behavior. We find inconclusive evidence that this assumption holds in our data - however, this is inconsequential for the validity of our mechanism and predictions. For our predictions to hold, it is sufficient if Citizens believe that corruption and trustworthiness behavior are negatively associated. Though our data cannot measure that, we conjecture people in general hold such beliefs. After all bribe demand and low trustworthiness are both social appropriateness norm violations. Fourth, unlike most other corruption experiments which are run in countries with low corruption norm, our experiments are conducted in a country where corruption is very high - India. Some of the results, interpretations and responses in this study may depend on cultural traits of subjects. Finally, despite the fact that corruption is almost always social welfare reducing, there may be circumstances where corruption is relatively more acceptable and thus may have a relatively favorable social norm e.g. collusive bribery. More research needs to be conducted to examine whether corruption induces trust deficit through norm violation channel in those situations. The kind of corruption we study, namely harassment bribery, is indeed one in a spectrum of possible strategic interactions that may find a place under the broad umbrella of corruption.

The consequences of corruption on economic activity has primarily been addressed in the 
literature through three channels: public and private investments and expenditure, human capital and governance. Our paper suggests that adverse effect on social capital is yet another way in which corruption can affect growth and other economic activity. This channel has received little attention in the literature and our paper takes a first step in that direction by showing that there is an unambiguous causal link from corruption to decay in social capital. Nietzsche's observation was of a personal nature but it may indeed have a wider, pan societal ramification.

\section{Acknowledgement}

I thank Alexander Koch, Nabanita Datta Gupta, Marco Piovesan, Luigi Zingales, Bertil Tungodden, Lata Gangadharan, Johannes Abeler, Emma von Essen, Klaus Abbink, Joydeep Bhattacharya, Parimal Bag, seminar/conference participants at Aarhus University, IIM Calcutta, IIT Gandhinagar, IIM Ahmedabad, Winter School at DSE 2014, Morality Conference at University of California, San Diego, Washington and Lee University and two anonymous referee for their comments and suggestions. I also thank Sujoy Chakrabarty and Bibek Banerjee for making it possible for me to run the experiment and Manas Pathak for his research assistance. The experiment was funded with grants from Department of Economics and Business, Aarhus University.

\section{References}

Abbink, Klaus and Danila Serra, "Anticorruption Policies: Lessons from the Lab," in Leonard Wantchekon Danila Serra, ed., New Advances in Experimental Research on Corruption, Emerald Group Publishing Limited, 2012, chapter 8, pp. 77-115.

_, Utteeyo Dasgupta, Lata Gangadharan, and Tarun Jain, "Letting the briber go free: An experiment on mitigating harassment bribes," Journal of Public Economics, 2014, 111 (C), $17-28$.

Abeler, Johannes, Armin Falk, Lorenz Goette, and David Huffman, "Reference Points and Effort Provision," American Economic Review, 2011, 101 (2), 470-92.

Acemoglu, Daron and Alexander Wolitzky, "Cycles of Conflict: An Economic Model," American Economic Review, 2014, 104 (4), 1350-67.

Ahn, T.K., Elinor Ostrom, David Schmidt, Robert Shupp, and James Walker, "Cooperation in PD Games: Fear, Greed, and History of Play," Public Choice, 2001, 106 (1-2), 137-155.

Albert, Max, Werner Guth, Erich Kirchler, and Boris Maciejovsky, "Are we nice(r) to nice(r) people?An experimental analysis," Experimental Economics, March 2007, 10 (1), 53-69. 
Anderson, Christopher J. and Yuliya V. Tverdova, "Corruption, Political Allegiances, and Attitudes toward Government in Contemporary Democracies," American Journal of Political Science, 2003, 47 (1), pp. 91-109.

Banerjee, Ritwik, "On the interpretation of bribery in a laboratory corruption game: moral frames and social norms," Experimental Economics, 2016, 19 (1), 240-267.

Bardhan, Pranab, "Corruption and Development: A Review of Issues," Journal of Economic Literature, September 1997, 35 (3), 1320-1346.

Bednar, Jenna, Yan Chen, Tracy Xiao Liu, and Scott Page, "Behavioral spillovers and cognitive load in multiple games: An experimental study," Games and Economic Behavior, 2012, $74(1), 12-31$.

Bellemare, Charles and Sabine Kroger, "On representative social capital," European Economic Review, January 2007, 51 (1), 183-202.

Berg, Joyce, John Dickhaut, and Kevin McCabe, "Trust, Reciprocity, and Social History," Games and Economic Behavior, July 1995, 10 (1), 122-142.

Bjornskov, Christian, "Combating Corruption: On the Interplay between Institutional Quality and Social Trust," Journal of Law and Economics, 2011, 54 (1), 135 - 159.

Bowler, S. and J. A. Karp, "Politicians, scandals, and trust in government," Political Behavior, 2004, 26 (3), 271-287.

Brandts, Jordi and David J. Cooper, "A Change Would Do You Good .... An Experimental Study on How to Overcome Coordination Failure in Organizations," American Economic Review, 2006, $96(3), 669-693$.

_ and Gary Charness, "The strategy versus the direct-response method: a first survey of experimental comparisons," Experimental Economics, 2011, 14 (3), 375-398.

Buchan, Nancy R., Rachel T.A. Croson, and Sara Solnick, "Trust and gender: An examination of behavior and beliefs in the Investment Game," Journal of Economic Behavior $\mathcal{G}$ Organization, December 2008, 68 (3-4), 466-476.

Burnham, Terence, Kevin McCabe, and Vernon L. Smith, "Friend-or-foe intentionality priming in an extensive form trust game," Journal of Economic Behavior 6 Organization, September 2000, 43 (1), 57-73.

Buser, Thomas and Anna Dreber, "The Flipside of Comparative Payment Schemes," Tinburgen Institute Discussion Paper TI 2013-190/1, Tinburgen Institute 2013. 
Casari, Marco and Timothy N. Cason, "The strategy method lowers measured trustworthy behavior," Economics Letters, June 2009, 103 (3), 157-159.

Cason, Timothy N. and Lata Gangadharan, "Cooperation Spillovers And Price Competition In Experimental Markets," Economic Inquiry, 07 2013, 51 (3), 1715-1730.

_, Anya C. Savikhin, and Roman M. Sheremeta, "Behavioral spillovers in coordination games," European Economic Review, 2012, 56 (2), 233 - 245.

Chang, Eric C. C. and Yun han Chu, "Corruption and Trust: Exceptionalism in Asian Democracies?," Journal of Politics, 2006, 68 (2), 259-271.

Chaudhuri, Ananish and Lata Gangadharan, "An Experimental Analysis of Trust and Trustworthiness," Southern Economic Journal, 2007, 73 (4).

_, Sarah Ali Khan, Aishwarya Lakshmiratan, Anne-Laure Py, and Lisa Shah, "Trust and trustworthiness in a sequential bargaining game," Journal of Behavioral Decision Making, 2003, 16 (5), 331-340.

Cherry, Todd L. and Jason F. Shogren, "Rationality crossovers," Journal of Economic Psychology, April 2007, 28 (2), 261-277.

_ , Thomas D. Crocker, and Jason F. Shogren, "Rationality spillovers," Journal of Environmental Economics and Management, January 2003, 45 (1), 63-84.

Cohn, Alain, Ernst Fehr, and Michel André Maréchal, "Business culture and dishonesty in the banking industry," Nature, 2014.

Croson, Rachel and Uri Gneezy, "Gender Differences in Preferences," Journal of Economic Literature, 2009, 47 (2), pp. 448-474.

Dasgupta, Utteeyo and Arjun Menon, "Trust and Trustworthiness among Economics Majors," Economics Bulletin, 2011, 31 (4), 2799-2815.

DellaPorta, D., "Social capital, beliefs in government and political corruption," in S. J. Pharr and R. D. Putnam, eds., Disaffected democracies: What's troubling the trilateral countries?, Princeton, NJ: Princeton University Press, 2000.

Dohmen, Thomas, Armin Falk, David Huffman, Uwe Sunde, Jurgen Schupp, and Gert G. Wagner, "Individual Risk Attitudes: Measurement, Determinants, And Behavioral Consequences," Journal of the European Economic Association, 06 2011, 9 (3), 522-550.

Drouvelis, Michalis, Robert Metcalfe, and Nattavudh Powdthavee, "Priming Cooperation in Social Dilemma Games," IZA Discussion Papers 4963, Institute for the Study of Labor (IZA) May 2010. 
Ellingsen, Tore, Magnus Johannesson, Johanna Mollerstrom, and Sara Munkhammar, "Social framing effects: Preferences or beliefs?," Games and Economic Behavior, 2012, 76 (1), $117-130$.

Gächter, Simon, Daniele Nosenzo, and Martin Sefton, "Peer Effects In Pro-Social Behavior: Social Norms Or Social Preferences?," Journal of the European Economic Association, 062013, $11(3), 548-573$.

Guiso, Luigi, Paola Sapienza, and Luigi Zingales, "The Role of Social Capital in Financial Development," American Economic Review, June 2004, 94 (3), 526-556.

_ , _ , and _ , "Trusting the Stock Market," Journal of Finance, December 2008, 63 (6), 2557-2600.

_ , _, and _ , "Cultural Biases in Economic Exchange?," The Quarterly Journal of Economics, August 2009, 124 (3), 1095-1131.

Güth, Warner and Martin Kocher, "More than thirty years of ultimatum bargaining experiments: Motives, variations and a survey of the recent literature," Journal of Economic Behavior E Organisation, 2014, 108 (C), 396-409.

Huck, Steffen, Philippe Jehiel, and Tom Rutter, "Feedback spillover and analogy-based expectations: A multi-game experiment," Games and Economic Behavior, March 2011, 71 (2), $351-365$.

Innes, Robert and Arnab Mitra, "Is Dishonesty Contagious?," Economic Inquiry, 012013,51 (1), 722-734.

Knack, Stephen and Philip Keefer, "Does Social Capital Have an Economic Payoff? A Cross-Country Investigation," The Quarterly Journal of Economics, 1997, 112 (4), 1251-1288.

Knez, M. and C. Camerer, "Increasing Cooperation in Prisoner's Dilemmas by Establishing a Precedent of Efficiency in Coordination Games," Organizational Behavior and Human Decision Processes, 2000, 82 (2), 194-216. cited By (since 1996)38.

Krupka, Erin L. and Roberto A. Weber, "Identifying Social Norms Using Coordination Games: Why Does Dictator Game Sharing Vary?," Journal of European Economic Association, 2012 .

LaPorta, Rafael, Florencio Lopez de Silanes, Andrei Shleifer, and Robert W. Vishny, "Trust in Large Organizations," American Economic Review, May 1997, 87 (2), 333-38.

López-Pérez, Raúl and Eli Spiegelman, "Do Economists Lie More?," Working Papers in Economic Theory 2012/04, Universidad Autónoma de Madrid (Spain), Department of Economic Analysis (Economic Theory and Economic History) 2012. 
Moreno, A, "Corruption and democracy: A cultural assessment," Comparative Sociology, 2002, 1 (3-4), 495-507.

Morris, Stephen D. and Joseph L. Klesner, "Corruption and Trust: Theoretical Considerations and Evidence From Mexico," Comparative Political Studies, 2010, 43 (10), 1258-1285.

North, Douglas C., Institutions Institutional Change and Economic Performance, Cambridge University Press, 1990.

Oxoby, Robert J. and John Spraggon, "Mine and yours: Property rights in dictator games," Journal of Economic Behavior 85 Organization, March 2008, 65 (3-4), 703-713.

Rothstein, B. and D. Stolle, "How Political Institutions Create and Destroy Social Capital: An Institutional Theory of Generalized Trust," Paper presented at the annual meeting of the American Political Science Association, Boston Marriott Copley Place, Sheraton Boston $\&$ Hynes Convention Center, Boston, Massachusetts, 2002.

Rotondi, Valentina and Luca Stanca, "The Effect of Particularism on Corruption: Theory and Empirical Evidence," Working Paper 294, University of Milan Bicocca Department of Economics, Management and Statistics February 2015.

Sah, Raaj, "Corruption across countries and regions: Some consequences of local osmosis," Journal of Economic Dynamics and Control, August 2007, 31 (8), 2573-2598.

Seligson, Mitchell A., "The Impact of Corruption on Regime Legitimacy: A Comparative Study of Four Latin American Countries," Journal of Politics, 2002, 64 (2), 408-433.

Serra, Danila and Leonard Wantchekon, "Experimental Research on Corruption: Introduction and Overview," in Leonard Wantchekon Danila Serra, ed., New Advances in Experimental Research on Corruption, Research in Experimental Economics, Emerald Group Publishing Limited, 2012, chapter 1, pp. 51-76.

Sobel, Joel, "Can We Trust Social Capital?," Journal of Economic Literature, 2002, 40 (1), 139-154.

Uslaner, E.M., The Moral Foundations of Trust, Cambridge University Press, 2002.

Weber, Roberto A., "Managing Growth to Achieve Efficient Coordination in Large Groups," American Economic Review, 2006, 96 (1), 114-126.

Williamson, Oliver E., The Economic Institutions of Capitalism, The Free Press: New York, 1985. 
Table 2: Citizen and Player A's Trust

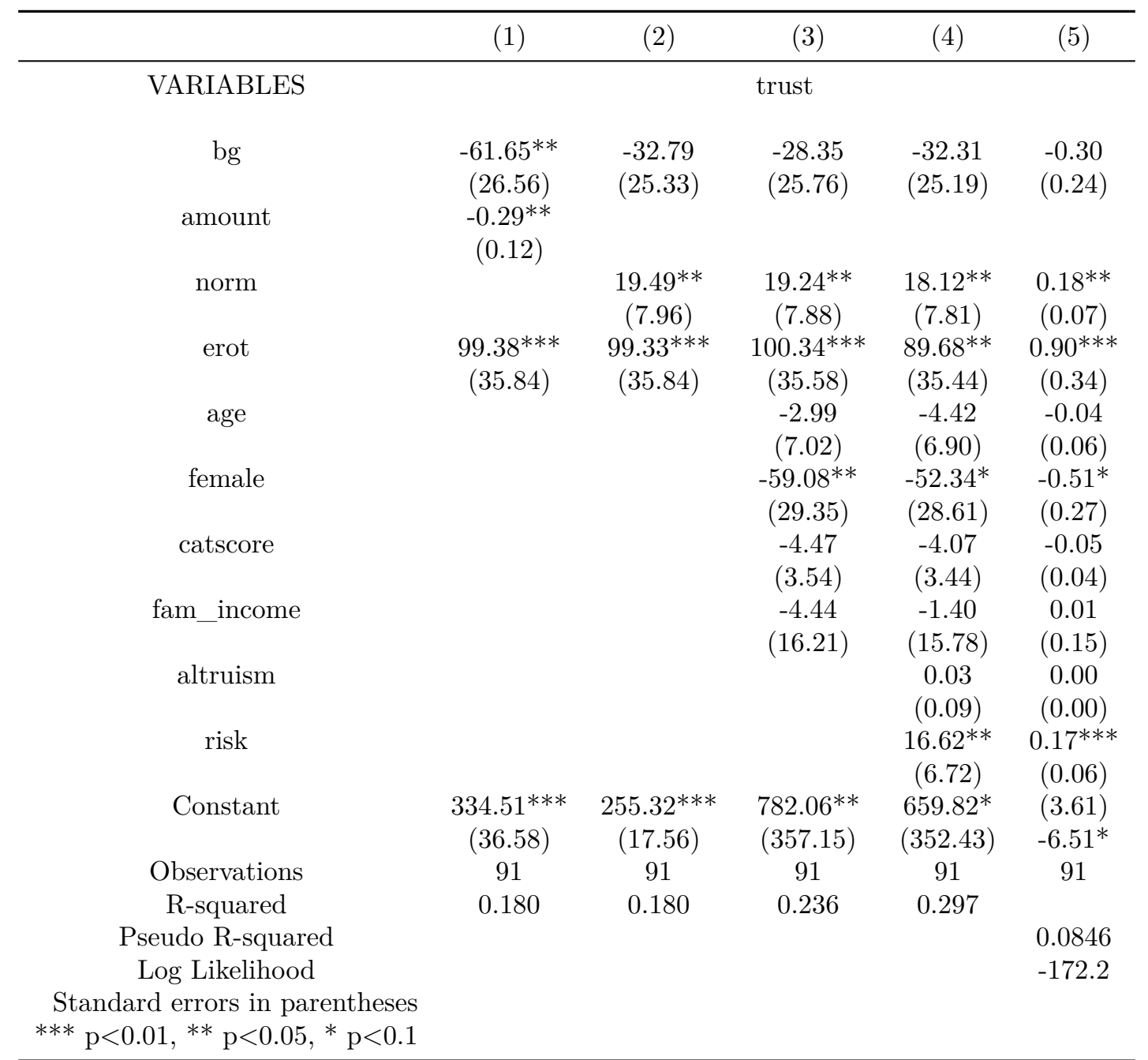

†† Note: Numbers in the parentheses are Standard errors. $* * *$ denotes significance at the $1 \%$ level, ** at the $5 \%$ level and $*$ at the $10 \%$ level. The dependent variable is trust. For definitions of the variables see Table 6 in Appendix 2. 
Table 3: Mechanism driving Citizen and Participant A's Trust and Trustworthiness decisions

\begin{tabular}{|c|c|c|c|c|c|c|}
\hline & (1) & $(2)$ & (3) & (4) & $(5)$ & (6) \\
\hline VARIABLES & & trust & & \multicolumn{3}{|c|}{ trustworthiness } \\
\hline $\mathrm{bg}$ & & & & $\begin{array}{c}0.02 \\
(0.03)\end{array}$ & $\begin{array}{c}0.03 \\
(0.03)\end{array}$ & $\begin{array}{c}0.03 \\
(0.03)\end{array}$ \\
\hline amount & & & & $\begin{array}{c}0.00 \\
(0.00)\end{array}$ & & \\
\hline norm & & & & & $\begin{array}{l}-0.01 \\
(0.01)\end{array}$ & $\begin{array}{l}-0.01 \\
(0.01)\end{array}$ \\
\hline erot & $\begin{array}{l}412.99^{*} \\
(223.93)\end{array}$ & $\begin{array}{l}395.08^{*} \\
(238.93)\end{array}$ & $\begin{array}{l}465.44^{\dagger} \\
(286.23)\end{array}$ & & $\begin{array}{c}0.21^{* * *} \\
(0.04)\end{array}$ & $\begin{array}{c}0.22^{* * *} \\
(0.04)\end{array}$ \\
\hline age & & $\begin{array}{l}-3.02 \\
(6.99)\end{array}$ & $\begin{array}{l}-4.49 \\
(7.00)\end{array}$ & & $\begin{array}{l}-0.00 \\
(0.01)\end{array}$ & $\begin{array}{l}-0.00 \\
(0.01)\end{array}$ \\
\hline female & & $\begin{array}{c}-59.31^{* *} \\
(29.82)\end{array}$ & $\begin{array}{l}-51.55^{*} \\
(31.30)\end{array}$ & & $\begin{array}{l}-0.01 \\
(0.03)\end{array}$ & $\begin{array}{l}-0.02 \\
(0.03)\end{array}$ \\
\hline score & & $\begin{array}{l}-4.46 \\
(3.51)\end{array}$ & $\begin{array}{l}-4.10 \\
(3.50)\end{array}$ & & $\begin{array}{l}-0.01 \\
(0.00)\end{array}$ & $\begin{array}{l}-0.01 \\
(0.00)\end{array}$ \\
\hline fam_income & & $\begin{array}{c}-3.93 \\
(19.29)\end{array}$ & $\begin{array}{c}-0.58 \\
(19.41)\end{array}$ & & $\begin{array}{l}0.03^{*} \\
(0.02)\end{array}$ & $\begin{array}{l}0.03^{*} \\
(0.02)\end{array}$ \\
\hline altruism & & & $\begin{array}{c}0.03 \\
(0.18)\end{array}$ & & & $\begin{array}{l}-0.00 \\
(0.00)\end{array}$ \\
\hline risk & & & $\begin{array}{c}17.64^{* *} \\
(7.03)\end{array}$ & & & $\begin{array}{l}-0.00 \\
(0.01)\end{array}$ \\
\hline Constant & $\begin{array}{c}242.86^{* * *} \\
(17.56)\end{array}$ & $\begin{array}{l}768.83^{* *} \\
(363.05)\end{array}$ & $\begin{array}{l}646.45^{*} \\
(358.56)\end{array}$ & $\begin{array}{c}0.38^{* * *} \\
(0.04)\end{array}$ & $\begin{array}{c}0.84^{* *} \\
(0.38)\end{array}$ & $\begin{array}{c}0.92^{* *} \\
(0.38)\end{array}$ \\
\hline $\begin{array}{c}\text { First Stage } \\
\text { bg }\end{array}$ & $\begin{array}{l}-0.13^{*} \\
(0.07)\end{array}$ & $\begin{array}{l}-0.12^{*} \\
(0.07)\end{array}$ & $\begin{array}{l}-0.11^{*} \\
(0.07)\end{array}$ & & & \\
\hline norm & $\begin{array}{l}0.03^{*} \\
(0.02)\end{array}$ & $\begin{array}{l}0.03^{*} \\
(0.02)\end{array}$ & $\begin{array}{l}0.03^{*} \\
(0.02)\end{array}$ & & & \\
\hline Constant & Yes & Yes & Yes & & & \\
\hline $\begin{array}{c}\text { Observations } \\
\text { R-squared }\end{array}$ & 91 & 91 & 91 & $\begin{array}{c}91 \\
0.003\end{array}$ & $\begin{array}{c}91 \\
0.311\end{array}$ & $\begin{array}{c}91 \\
0.322\end{array}$ \\
\hline $\begin{array}{l}\text { Pseudo R-squared } \\
\text { Log Likelihood }\end{array}$ & & & & & & \\
\hline
\end{tabular}

$\dagger$ The coefficient is marginally insignificant with $\mathrm{p}$-value $=0.10$

$\dagger \dagger$ Numbers in the parentheses are Standard errors. *** denotes significance at the $1 \%$ level, ${ }^{* *}$ at the $5 \%$ level and $*$ at the $10 \%$ level. The dependent variable in col (1) - (3) is trust, that in col (4) - (6) is trustworthiness measured as average Return Ratio. Col (1) - (3) jointly estimate average ERoT and trust. 
Table 4: Public Official's Trust

\begin{tabular}{|c|c|c|c|c|}
\hline & (1) & $(2)$ & $(3)$ & $(4)$ \\
\hline VARIABLES & & $\operatorname{tr} 1$ & & \\
\hline bribe & $\begin{array}{c}-0.28^{*} \\
(0.15)\end{array}$ & $\begin{array}{l}-0.30^{*} \\
(0.15)\end{array}$ & & \\
\hline norm & & & $\begin{array}{l}21.04^{*} \\
(11.53)\end{array}$ & $\begin{array}{c}23.30^{* *} \\
(10.94)\end{array}$ \\
\hline age & & $\begin{array}{c}0.04 \\
(11.19)\end{array}$ & $\begin{array}{c}-0.46 \\
(11.81)\end{array}$ & $\begin{array}{c}-0.62 \\
(11.17)\end{array}$ \\
\hline female & & $\begin{array}{l}-21.01 \\
(41.48)\end{array}$ & $\begin{array}{l}-19.44 \\
(43.56)\end{array}$ & $\begin{array}{l}-22.30 \\
(41.27)\end{array}$ \\
\hline catscore & & $\begin{array}{c}-0.36^{*} \\
(0.20)\end{array}$ & $\begin{array}{c}-0.39^{*} \\
(0.21)\end{array}$ & $\begin{array}{c}-0.35^{*} \\
(0.20)\end{array}$ \\
\hline fam_income & & $\begin{array}{c}10.29 \\
(27.28)\end{array}$ & $\begin{array}{c}18.32 \\
(28.48)\end{array}$ & $\begin{array}{c}10.55 \\
(27.11)\end{array}$ \\
\hline altruism & & $\begin{array}{l}-0.12 \\
(0.13)\end{array}$ & & $\begin{array}{c}-0.12 \\
(0.12)\end{array}$ \\
\hline risk & & $\begin{array}{c}22.98^{* *} \\
(9.44)\end{array}$ & & $\begin{array}{c}22.77^{* * *} \\
(9.37)\end{array}$ \\
\hline Constant & $\begin{array}{c}305.65^{* * *} \\
(32.10)\end{array}$ & $\begin{array}{c}232.78 \\
(310.25)\end{array}$ & $\begin{array}{c}249.98 \\
(312.12)\end{array}$ & $\begin{array}{c}199.15 \\
(305.51)\end{array}$ \\
\hline $\begin{array}{r}\text { Observations } \\
\text { R-squared }\end{array}$ & $\begin{array}{c}46 \\
0.076\end{array}$ & $\begin{array}{c}46 \\
0.287\end{array}$ & $\begin{array}{c}46 \\
0.169\end{array}$ & $\begin{array}{c}46 \\
0.295\end{array}$ \\
\hline
\end{tabular}


Table 5: Effect of trust on Receiver's demand for bribe

\begin{tabular}{|c|c|c|c|c|c|c|c|}
\hline & & (1) & $(2)$ & $(3)$ & $(4)$ & $(5)$ & (6) \\
\hline \multirow[t]{9}{*}{ EQUATION } & VARIABLES & \multicolumn{6}{|c|}{ bribe } \\
\hline & trust & $\begin{array}{l}-0.20 \\
(0.18)\end{array}$ & & & & & \\
\hline & norm & & $\begin{array}{c}12.93 \\
(44.51)\end{array}$ & & & & \\
\hline & female & & $\begin{array}{l}-43.97 \\
(39.52)\end{array}$ & & $\begin{array}{l}-46.87 \\
(33.18)\end{array}$ & & $\begin{array}{c}-46.41 \\
(36.99)\end{array}$ \\
\hline & age & & $\begin{array}{c}5.47 \\
(17.25)\end{array}$ & & $\begin{array}{c}0.60 \\
(18.86)\end{array}$ & & $\begin{array}{c}0.56 \\
(15.67)\end{array}$ \\
\hline & income & & $\begin{array}{l}-23.22 \\
(20.48)\end{array}$ & & $\begin{array}{c}-22.74 \\
(19.26)\end{array}$ & & $\begin{array}{l}-22.61 \\
(19.03)\end{array}$ \\
\hline & score & & $\begin{array}{l}-4.74 \\
(3.44)\end{array}$ & & $\begin{array}{c}-4.77^{*} \\
(2.88)\end{array}$ & & $\begin{array}{l}-4.74 \\
(3.22)\end{array}$ \\
\hline & expect_bribe_accept & & & $\begin{array}{c}131.00 \\
(149.54)\end{array}$ & $\begin{array}{c}47.18 \\
(132.28)\end{array}$ & $\begin{array}{c}58.33^{* *} \\
(26.40)\end{array}$ & $\begin{array}{c}55.59^{* *} \\
(26.14)\end{array}$ \\
\hline & Constant & $\begin{array}{c}185.72^{* * *} \\
(37.11)\end{array}$ & $\begin{array}{c}374.27 \\
(484.48)\end{array}$ & $\begin{array}{l}-112.00 \\
(299.63)\end{array}$ & $\begin{array}{c}479.99 \\
(399.09)\end{array}$ & $\begin{array}{c}33.33 \\
(55.38)\end{array}$ & $\begin{array}{c}461.49 \\
(446.19)\end{array}$ \\
\hline \multirow[t]{4}{*}{ First stage } & norm & & & $\begin{array}{c}0.29 \\
(0.27)\end{array}$ & $\begin{array}{c}0.29 \\
(0.27)\end{array}$ & & \\
\hline & Constant & & & $\begin{array}{c}1.63^{* * *} \\
(0.36)\end{array}$ & $\begin{array}{c}1.63^{* * *} \\
(0.36)\end{array}$ & & \\
\hline & Observations & 30 & 30 & 30 & 30 & 30 & 30 \\
\hline & R-squared & 0.041 & 0.209 & & & 0.148 & 0.306 \\
\hline
\end{tabular}

\footnotetext{
${ }^{\dagger}$ Numbers in the parentheses are Standard errors. ${ }^{* * *}$ denotes significance at the $1 \%$ level, ${ }^{* *}$ at the $5 \%$ level and ${ }^{*}$ at the $10 \%$ level. The dependent variable is the amount of bribe demanded. Trust level exhibited in the first stage does not predict bribe demanded in the second stage. Col (3) and (4) estimates the two stage regression analogous to col (1) - (3) in Table 3. Col (5) and (6) demonstrates that expectations about acceptance of bribe demand significantly predicts the amount demanded. For definitions of the variables see Table 6 in Appendix 2.
} 


\section{Appendix 1: Theoretical Framework}

Assume that a person, who is trustworthy, is more likely to be honest, say with probability $h$, than a person who is untrustworthy, say $l$, such that $0 \leq l<h \leq 1$. Also assume that a Bayesian Citizen gets an imperfect signal about trustworthiness of the set of matched partners by observing whether she meets an honest official or a corrupt one in the first stage. Then she uses this signal to update his posterior belief that a matched person in the second stage is trustworthy. Note that unlike in typical applications where a Bayesian agent updates her belief about exactly the same individual she meets, we follow Acemoglu and Wolitzky (2014) and assume that a Citizen learns something about how subjects, in the pool of matched Public Officials she is dealing with, are by observing examples of their behavior. Bayesian updating then tends to make Citizens put more weight on the behavior they immediately observe.

Let $\mu_{0}$ be the prior belief that a matched partner is trustworthy. Suppose that a Citizen meets an honest official in the first stage. His updated posterior about a matched partner's trustworthiness in the second stage, $\mu$ is given by

$$
\mu(H)=\frac{\mu_{0} h}{\mu_{0} h+\left(1-\mu_{0}\right) l}
$$

This follows in view of the fact that the official is either honest and trustworthy (probability $\left.\mu_{0} h\right)$ or an honest official coming from that subset of officials who are not trustworthy (probability $\left.\left(1-\mu_{0}\right) l\right)$. Similarly, given that a Citizen meets a corrupt person in the first stage, his updated posterior is given by

$$
\mu(L)=\frac{\mu_{0}(1-h)}{\mu_{0}(1-h)+\left(1-\mu_{0}\right)(1-l)}
$$

It is easy to see that the $\mu(H)>\mu_{0}$ and $\mu(L)<\mu_{0}$ i.e. the posterior belief of a Citizen about meeting a trustworthy person in the future is higher if she meets an honest Public Official while it is lower if she meets a corrupt Public Official. This leads to our first prediction.

Prediction 1. If a Citizen meets a corrupt (honest) Public Official, then her belief about the trustworthiness of the person she will meet in the second stage decreases (increases).

The updated beliefs play an important role in the subsequent trust decision, which we model as that in a simple trust game. Assume that the initial endowment in the trust game is given by $\bar{x}$, sharing decision by $t$ and there are only two types of receivers with whom the sharing decisions are made - one, less trustworthy i.e. those who keep a high amount with themselves (say $\bar{w}$ ) and two, more trustworthy i.e. those who keep a small amount with themselves (say $\underline{\mathrm{w}}$ ). Preferences of 
those making the trust decisions are given by $U(., \lambda, \theta)$ where $\lambda$ and $\theta$ are the risk (implicit in the curvature of the utility function) and pro-sociality parameter.

Expected Utility of an individual who shares $s$ as a sender in the trust game is given by -

$$
E U=\mu U(\bar{x}-t+(3 t-\underline{\mathrm{w}}), \lambda, \theta)+(1-\mu) U(\bar{x}-t+(3 t-\bar{w}), \lambda, \theta)
$$

Assuming an interior solution ${ }^{13}$, the first order condition with respect to $t$ is given by

$$
\begin{aligned}
2 \mu U_{1}\left(\bar{x}+2 t^{*}-\underline{\mathrm{w}}, \lambda, \theta\right)+2(1-\mu) U_{1}\left(\bar{x}+2 t^{*}-\bar{w}, \lambda, \theta\right) & =0 \\
t^{*} & =t^{*}(\mu, \lambda, \theta)
\end{aligned}
$$

Plugging equation (3) in (6) gives the optimal trust decision if one meets an honest person before, $t^{*}(H)=t^{*}(\mu(H), \lambda, \theta)$, while plugging equation (4) in (6) gives the optimal trust decision if one meets a dishonest person before, $t^{*}(L)=t^{*}(\mu(L), \lambda, \theta)$.

Prediction 2. If a Citizen meets a corrupt (honest) Public Official, then the trust shown by the Citizen decreases (increases).

Totally differentiating the first order condition with respect to $t$ and $\mu$, we can show that $\frac{d t^{*}}{d \mu}>0$. Since $\mu(H)>\mu_{0}$ and $\mu(L)<\mu_{0}$ implies $\mu(H)>\mu(L)$, it follows that $t^{*}(\mu(H), \lambda, \theta)>t^{*}(\mu(L), \lambda, \theta)$.

Our interest lies in estimating how trust responds to whether a Citizen meets an honest official or a corrupt one. We therefore estimate equation (6) from the framework described above. The linear approximation to the functional form in equation (6) is

$$
t=\beta_{\mu} \mu+\beta_{\lambda} \lambda+\beta_{\theta} \theta+\varepsilon
$$

The specification in (7) shows that trust decision is predicted by the belief of the Citizen about how trustworthy the trustee is, the risk preference and pro-sociality parameters and a disturbance term. However, notice that $\mu$ is determined at the previous stage and thus equation (7) is jointly estimated with equation (8)

$$
\mu=\gamma \mathbf{1}(H)+\nu
$$

where $\mathbf{1}(H)$ is a dummy variable indicating whether the Citizen meets an honest official or not and $\nu$ is the disturbance term. The data from the experiment allow us to jointly estimate (7) and (8), as is described in Subsection 3.3.

\footnotetext{
${ }^{13}$ In this framework $t^{*}>0$ iff $E U\left(t^{*}\right) \geq U(\bar{x})$ i.e. an individual decides to share iff his expected return from sharing is higher than that from retaining the entire amount with himself.
} 


\section{Appendix 2 (Supplementary Online Material)}

Table 6: Summary Statistics

\begin{tabular}{|c|c|c|c|c|c|}
\hline BG/UG Variables & Description & \multicolumn{2}{|c|}{ Mean } & \multicolumn{2}{|c|}{ Std. Dev } \\
\hline bg & $=1$ if Treatment is BG & \multicolumn{2}{|c|}{0.51} & \multicolumn{2}{|c|}{0.50} \\
\hline amount & amount demanded from $\mathrm{C} / \mathrm{P}-\mathrm{A}$ & \multicolumn{2}{|c|}{232.97} & \multicolumn{2}{|c|}{109.60} \\
\hline bribe & bribe demanded by $\mathrm{PO}$ in $\mathrm{BG}$ & \multicolumn{2}{|c|}{225.27} & \multicolumn{2}{|c|}{110.14} \\
\hline norm & $\begin{array}{c}\text { Mean Social appropriateness measure for a } \\
\text { amount }\end{array}$ & \multicolumn{2}{|c|}{-0.17} & \multicolumn{2}{|c|}{1.57} \\
\hline Observations & & \multicolumn{2}{|c|}{91} & & \\
\hline \multirow{2}{*}{ Trust Game \& Demographic Variables } & & \multicolumn{2}{|c|}{ Full Sample } & \multicolumn{2}{|c|}{$\mathrm{C}+\mathrm{P}-\mathrm{A}+$ Baseline } \\
\hline & & Mean & Std. Dev. & Mean & Std. Dev. \\
\hline trust & Amount sent as a sender in Trust Game & 245.41 & 122.29 & 232.97 & 127.20 \\
\hline trustworthiness & $\begin{array}{c}\text { Return Ratio, averaged over all trust } \\
\text { categories. }\end{array}$ & 0.39 & 0.14 & 0.39 & 0.14 \\
\hline erot & ERoT, averaged over all trust categories. & -0.02 & 0.41 & -0.02 & 0.35 \\
\hline female & $=1$ if subject is Female & 0.26 & 0.44 & 0.25 & 0.44 \\
\hline age & Age & 24.37 & 1.81 & 24.35 & 1.86 \\
\hline score & CAT/GMAT score in percentile & 100.32 & 55.98 & 95.06 & 3.51 \\
\hline fam_income & Family Income ${ }^{a}$ & 3.56 & 0.78 & 3.57 & 0.79 \\
\hline altruism & $\begin{array}{l}\text { Suppose you win a lottery of Rs. } 1000 \text {. How } \\
\text { much of it will you be willing to share with a } \\
\text { charity of your choice? }\end{array}$ & 294.27 & 142.32 & 283.52 & 141.43 \\
\hline risk & $\begin{array}{l}\text { How do you see yourself: are you generally a } \\
\text { person who is fully prepared to take risks or } \\
\text { do you try to avoid taking risks? }\end{array}$ & 5.76 & 2.00 & 5.90 & 1.86 \\
\hline Cronbach's alpha for Return $\operatorname{Ratio}^{b}$ & & & .86 & & .86 \\
\hline Cronbach's alpha for ERoT ${ }^{b}$ & & & .92 & & .90 \\
\hline Observations & & & 218 & & 91 \\
\hline
\end{tabular}

${ }^{a}$ Categorical variable where category 1: <Rs. 20,000, 2: between Rs. 20,001 and Rs. 50,000, 3: between Rs. 50,001 and Rs. 1,00,000 and 4: >Rs. $1,00,001$.

${ }^{b}$ A measure of internal consistency, i.e. how closely related the set of items are as a group. 


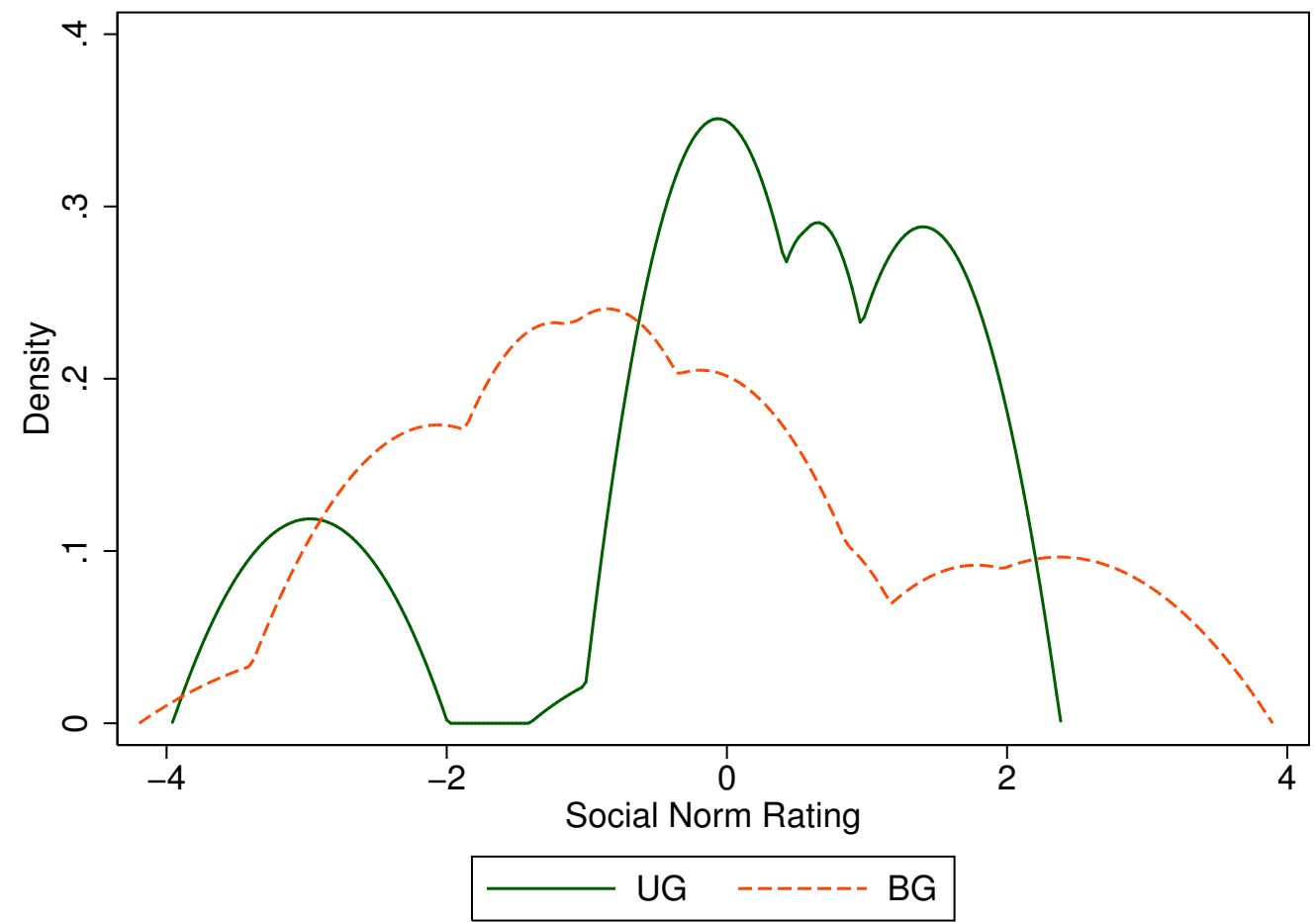

Figure 6: Distribution of social norm corresponding to actual amount demanded in UG and BG The figure plots the Epanechnikov kernel density estimate of the social norm corresponding to the amount demanded in UG and BG. There is relatively more mass on the left for BG than UG indicating that more socially inappropriate demand has been made in the former than the latter. 
Table 7: Frequency distribution of norm ratings for each amount demanded in BG and UG

\begin{tabular}{|c|c|c|c|c|c|c|c|c|c|c|c|c|c|c|c|c|c|c|}
\hline Amount Demanded & -3 & -2 & -1 & 0 & 1 & 2 & 3 & Mean UG & \multirow{4}{*}{$-B G$} & -3 & -2 & -1 & 0 & 1 & 2 & 3 & Mean BG & $p$-value ${ }^{a}$ \\
\hline 0 & 55 & 10 & 10 & 0 & 2.5 & 5 & 17.5 & -1.3 & & 7.5 & 0 & 0 & 5 & 0 & 2.5 & 85 & 2.38 & 0.00 \\
\hline 100 & -UG ${ }^{12.5}$ & 32.5 & 10 & 5 & 10 & 30 & 0 & -0.43 & & 0 & 10 & 25 & 10 & 20 & 35 & 0 & 0.45 & 0.03 \\
\hline 200 & 0 & 5 & 2.5 & 25 & 10 & 30 & 27.5 & 1.4 & & 0 & 30 & 17.5 & 27.5 & 12.5 & 7.5 & 5 & -0.35 & 0.00 \\
\hline 300 & 5 & 25 & 17 & 0 & 30 & 17.5 & 5 & -0.03 & & 27.5 & 32.5 & 40 & 0 & 0 & 0 & 0 & -1.88 & 0.00 \\
\hline 400 & 97.5 & 2.5 & 0 & 0 & 0 & 0 & 0 & -2.98 & & 92.5 & 2.5 & 5 & 0 & 0 & 0 & 0 & -2.68 & 0.29 \\
\hline
\end{tabular}

${ }^{a}$ Mann Whitney Rank Sum test reported p-value of the mean difference. Shaded cells for each category in each treatment denote the modal ratings. 


\section{Appendix 3: Instructions (Supplementary Online Material)}

\section{Instructions for First Experiment (Bribery and Ultima- tum Games followed by Trust Game)}

\section{Welcome.}

You are now taking part in an economic experiment. If you read the following instructions carefully, you can, depending on your decisions and the decisions of other participants, earn a considerable amount of money. It is prohibited to communicate with the other participants during the experiment. Should you have any questions please raise your hand and we will come to you. This is an anonymous experiment and you will not know either the identity or the choices that others know. We will give each one of you an identity number which will facilitate your payments.

\section{Overview}

The experiment consists of 2 parts and a survey. Please start by reading the instructions for the first part carefully. You will receive the instructions for the second part after the first part is finished. And so on.

\section{Earnings}

During the experiment you can earn money by receiving a fictitious currency called "mohar". All mohars that you earn in the experiment will be exchanged into Rupees at the end of the experiment, The exchange rate is: 1 mohar $=$ Rs 0.50 ( $\mathrm{M}$ denotes mohar henceforth). We will pay you 200 mohars for participating but you can earn additional money depending on the decisions you and the others make. The experiment consists of two parts but remember you will be randomly paid for only one of the two parts which will be determined by a toss. Since you donot know which one you will be paid for, make your decisions for both the parts carefully.

\subsection{Part 1 : Subject given either 5.1.1 or 5.1.2}

\subsubsection{Bribery Game}

You may be paired with another participant in this experiment. The matching of two participants will be randomly done. You will not be informed of the identity of the participant with whom you have been matched.

Each participant today will receive a base participation fee of $200 \mathrm{M}$. We have divided the total number of participants in this experiment session randomly into two equal groups: Citizens $(\mathrm{C})$ and Public Officials (PO).

A Citizen performs a task in ten minutes. Her task is to count the number of occurrences of the letter "A" from a random sequence of letters. She has to perform this task for five different sequences of letters. If she is unable to complete the task in ten minutes then she leaves the game with her participation fee of $200 \mathrm{M}$ and the Public Official gets $600 \mathrm{M}$. If she successfully does complete the task she is entitled to a payment of $400 \mathrm{M}$ (in addition to participation fee of 200 $\mathrm{M})$. However before the experimenter hands over the entitlement to the Citizen, she needs the approval of the Public Official who receives a salary of $400 \mathrm{M}$ for his job of approval (in addition to participation fee of $200 \mathrm{M}$ ). A Public Official, however, can ask for a bribe before approving the entitlement for the corresponding Citizen. He may ask for a bribe of 100, 200, 300, 400 M. He may 
choose not to ask for a bribe as well i.e. ask for 0 bribe. The information for demand for bribe then is forwarded to the Citizen who can then decide whether to Accept or Reject the demand for bribe. The final earnings will depend on the final choices each one makes i.e. PO's choices about demand for bribe, C's choices about Acceptance or Rejection. Suppose PO demands a bribe $b$. If C accepts the demand then $\mathrm{PO}$ gets $(600+b) \mathrm{M}$ and $\mathrm{C}$ gets $(200+b) \mathrm{M}$. If she rejects the earnings then $\mathrm{C}$ and $\mathrm{PO}$ get only $600 \mathrm{M}$ and $200 \mathrm{M}$, respectively.

Take a look at the figure below to further clarify the rules of the game and the earnings.

Please go through the two examples given below.

Example. Citizen completes the task. She is entitled to a payment of $600 \mathrm{M}$. Public Official demands a bribe of $100 \mathrm{M}$ for himself. Citizen accepts it. Public Official's earning is $200+400+100=700$ M. Citizen's earning is $200+400-100=500 \mathrm{M}$.

Example. Citizen completes the task. She is entitled to a payment of $600 \mathrm{M}$. Public Official demands for a bribe of $400 \mathrm{M}$ for himself. Citizen rejects it. Public Official's earning is $600+0=600$ M. Citizen's earning is $200+0=200 \mathrm{M}$.

\section{Instruction for Citizens}

In this room all of you are Citizens. Note that you are matched anonymously with a participant sitting in the other room. He is your corresponding Public Official who is in charge of approving your entitlement if you do earn it.

In order to earn the entitlement of $400 \mathrm{M}$, you have to perform a simple task in 10 minutes following which you will earn the key to your entitlement. What you will see is five sequences of some random letters. Your task is to count the exact number of 'A's for each of the sequences. Only when you have correctly counted the number of As for a sequence will you be able to go to the next sequence. When you count successfully for all the sequence you will receive the key for your entitlement and you can use the key to make your choices subsequently.

In order to complete the task, click here to count the number of As for the five sequences of random letters.

1. Input your Identity number. Enter the correct the number of 'A's for each of the five sequences.

2. If you have completed counting the number of As, please write down the Key to your entitlement on a piece of paper and proceed. If you have not been able to complete the task in ten minutes then you can collect your participation fee and leave.

Right click here and open the link in a new tab to input your choices

3. If you believe you have successfully completed the task, please indicate how much bribe you think will be demanded from you by the public official. Think carefully before mentioning what you think the public official will do. You will receive an additional 100 Mohors if your answer matches with what the public official's decision. [The question was asked in Experiment 2 only.]

4. Please indicate on the response sheet and on the website whether you accept or reject the demand for bribe for all possible bribe amount. We will match your response with the actual bribe amount demanded and determine your earnings.

5. We will now collect your responses and match them with the response of your corresponding Public Official.

6. You will now receive the response sheet, which mentions the bribe demanded, your acceptance/rejection decision and the final earning from this part.

\section{Instruction for Public Officials}

In this room all of you are Public Officials. You are responsible for the approving the entitlement for the Citizens. Before approving you can ask for a bribe from the Citizen. You may also choose not to ask for a bribe. 
1. Please mention whether you think the citizen will accept/reject your demand, for every possible bribe amount. Think carefully before mentioning what you think the public official will do. You will receive an additional 100 Mohors if your answer matches with the citizen's actual action. [The question was asked in Experiment 2 only.]

2. Now make your decision whether to ask for a bribe before you approve the entitlement for the Citizen and if yes how much to ask for. Click here to input your choice.

2. We now collect your decision and match them with Citizen's acceptance/rejection decision.

\subsubsection{Ultimatum Game}

\section{Common for Participant A and Participant B}

You may be paired with another participant in this experiment. The matching of two participants will be randomly done. You will not be informed of the identity of the participant with whom you have been matched.

Each participant today will receive a base participation fee of $200 \mathrm{M}$. We have divided the total number of participants in this experiment session randomly into two equal groups: Participant A (P-A) and Participant B (P-B).

Participant A performs a task in ten minutes. Her task is to count the number of occurrences of the letter "A" from a random sequence of letters. She has to perform this task for five different sequences of letters. If she cannot perform the task in ten minutes then she leaves the game with her participation fee $200 \mathrm{M}$ and P-B gets $600 \mathrm{M}$. If she successfully completes the task, then she is entitled to playing the next stage of the game i.e. she earns the right to play the second stage game. P-B's earning is $400 \mathrm{M}$ in addition to the participation fee of $200 \mathrm{M}$ (i.e. $600 \mathrm{M}$ ) for her role, which is the following. In the second stage $\mathrm{P}-\mathrm{B}$ decides to divide $400 \mathrm{M}$ between himself and $\mathrm{P}-\mathrm{A}$. For example if P-B keeps $\mathrm{x}$ with himself then P-A gets $400-\mathrm{x}$ M. The amount which P-B transfers can only be in multiple of 100 s i.e. either $0,100,200,300,400$ in which cases he gets 400 , 300, 200, 100, 0, respectively, for himself. P-A can then decide whether or not to Accept or Reject the amount which is offered. If P-A accepts the offer then P-B gets $(600+\mathrm{x}) \mathrm{M}$ and P-A gets $(200$ $+\mathrm{x}) \mathrm{M}$. If she rejects the earnings then P-A and P-B get only $600 \mathrm{M}$ and $200 \mathrm{M}$ respectively.

Take a look at the figure below to further clarify the rules of the game and the earnings.

Please go through the two examples given below.

Example. P-A completes the task and proceeds to the next round. P-B divides $400 \mathrm{M}$ into 100 $\mathrm{M}$ for himself and $300 \mathrm{M}$ for himself. P-A accepts it. P-B's earning is $200+400+100=700 \mathrm{M}$. P-A's earning is $200+400-100=500 \mathrm{M}$.

Example. P-A completes the task and proceeds to the next round. P-B divides $400 \mathrm{M}$ into $400 \mathrm{M}$ for himself and 0 for P-A. P-A rejects it. P-B's earning is $600+0=600 \mathrm{M}$. P-A's earning is $200+0=200 \mathrm{M}$.

\section{Instruction for Participant A}

In this room all of you are Participant As. Note that you are matched anonymously with a participant sitting in the other room, he is your corresponding Participant B whom you will play in second round.

In order to proceed to second round, you will have to perform a simple task in 10 minutes following which you will earn the key to the second round. What you will see is five sequences of some random letters. Your task is to count the exact number of 'A's for each of the sequences. Only when you have correctly counted the number of As for a sequence will you be able to go to the next sequence. When you count successfully for all the sequence you will receive the key and 
you can use the key to proceed.

1. Right click here and open the link in a new tab. Enter the correct the number of 'A's for each of the five sequences.

2. If you have completed counting the number of As, please write down the Key to your entitlement on a piece of paper and proceed. If you have not been able to complete the task in ten minutes then you can collect your participation fee and leave.

3. Please right click here and open a new tab and indicate on the response sheet whether you accept or reject the amount demanded for all possible transfer amount. We will match your response with the actual transfer amount and determine your earnings.

4. We will now collect your responses and match them with the response of your corresponding P-B.

5. You will now receive the response sheet, which mentions the division proposed by P-B, your acceptance/rejection decision and the final earnings from this part.

\section{Instruction for Participant B}

In this room all of you are Participant B.

1. Now make your decision about how to divide $400 \mathrm{M}$ between yourself and Participant $\mathrm{A}$ i.e. whether to share anything with him, if yes how much. Please right click here to open a new link and input your decision. Your sharing amount should be in multiples of 100 .

2. We now collect your decision.

3. You are now being informed about whether your decision has been accepted and your and the P-A's earnings.

\subsection{Part 2: Trust Game: Common for Citizen and Public Official in BG and Participant A and Participant B in UG}

In this part a participation fee of $200 \mathrm{M}$ will be given to all participants.

You will now play the sending task. In this task, participants are divided into two groups: Senders and Receivers. Both the Senders and the Receivers are given 400 M. First Sender makes a decision. The Sender can choose to send 0, 100, 200, 300 or 400 M to the Receiver. Any amount sent will be tripled. The Sender keeps any amount of money not send to the Receiver.

The Receiver can send back any amount up to the total amount received (that is, the amount the Sender sent multiplied by 3).

Earnings The Sender's earnings in part 2 are $:=400 \mathrm{M}$ - any amount sent to the Receiver + any amount sent back to the Sender

The Receiver's earnings in part 2 are: = any amount received from the Sender multiplied by three - any amount sent back to the Sender.

You will be asked to make a decision both as a Sender and as a Receiver. One of your roles will be randomly picked. You will be matched with another randomly matched participant in the other role (note that your matched partner here will be different from the matched partner in Part 1). Your decision and the decision of the other player determine your earnings.

\section{Example}

You are in the role of a Sender. You have chosen to send 200 M to the Receiver. Hence, the Receiver could send back between 0 and $600 \mathrm{M}(=3 \times 200 \mathrm{M})$. to you. The Receiver has chosen to send back $300 \mathrm{M}$ to you.

- Your earnings in Part 2 are therefore: 400 M - 200 M (the amount you sent) + $300 \mathrm{M}$ (the amount received back) $=500 \mathrm{M}$. 
- The earnings of the Receiver in Part 2 are therefore: $600 \mathrm{M}$ (amount sent to the Receiver) $300 \mathrm{M}$ (amount sent back by the Receiver) $=300 \mathrm{M}$

You are in the role of a Receiver. The Sender has chosen to send $400 \mathrm{M}$ to you. Hence, you could send back between 0 and $1200 \mathrm{M}(=3 \times 400 \mathrm{M})$ to the Sender. You have chosen to send back $100 \mathrm{M}$ to the Sender.

- Your earnings in part 2 are therefore: $1100 \mathrm{M}=1200 \mathrm{M}$ (the amount you received) - $100 \mathrm{M}$ (the amount you sent back).

- The earnings of the Sender in part 2 are therefore : $100 \mathrm{M}=400-400+100=100 \mathrm{M}$

Practice exercise.

- You are in the role of a Sender. You have chosen to send 100 M to the Receiver. The Receiver has chosen to send back $0 \mathrm{M}$ to you.

Your earnings in part 4 are: The earnings of the Receiver in part 4 are:

- You are in the role of a Receiver. The Sender has chosen to send $300 \mathrm{M}$ to you. You have chosen to send back $100 \mathrm{M}$ to the Sender.

Your earnings in part 2 are:

The earnings of the Sender in part 2 are:

To make your decisions, right click here and open a new tab.

\section{Decision as Sender}

1. Mark how much you will like to send the receiver. (in multiples of $50 \mathrm{M}$ )

2. How much you expect the receiver to return you back if you send him $100 \mathrm{M}$ (i.e. Receiver receives $300 \mathrm{M}$ ). If your prediction matches the actual decision of the matched receiver then you will win a bonus of $100 \mathrm{M}$. While making your decision choose between 0,100, 200 or 300 only. (Please mention in multiples of $50 \mathrm{M}$ )

3. How much you expect the receiver to return you back if you send him 200 M (i.e. Receiver receives $600 \mathrm{M}$ ). If your prediction matches the actual decision of the matched receiver then you will win a bonus of $100 \mathrm{M}$. While making your decision choose between 0,100, 200, 300, 400, 500 or 600 only. (Please mention in multiples of $50 \mathrm{M}$ )

4. How much you expect the receiver to return you back if you send him $300 \mathrm{M}$ (i.e. Receiver receives $900 \mathrm{M}$ ). If your prediction matches the actual decision of the matched receiver then you will win a bonus of $100 \mathrm{M}$. While making your decision choose between 0,100, 200, 300, 400, 500, 600, 700, 800 and 900 only. (Please mention in multiples of $50 \mathrm{M}$ )

5. How much you expect the receiver to return you back if you send him $400 \mathrm{M}$ (i.e. Receiver receives $1200 \mathrm{M}$ ). If your prediction matches the actual decision of the matched receiver then you will win a bonus of $100 \mathrm{M}$. While making your decision choose between 0,100, 200, 300, 400, 500, 600, 700, 800, 900 1000, 1100 or 1200 only. (Please mention in multiples of $50 \mathrm{M}$ )

\section{Decision as Receiver}

1. Mark how much you will like to send back to the sender if you received $150 \mathrm{M}$ ( i.e. the sender sent you $50 \mathrm{M}$ ). Choose between 0 and 150 but in multiples of 50 only

2. Mark how much you will like to send back to the sender if you received $300 \mathrm{M}$ ( i.e. the sender sent you $100 \mathrm{M}$ ). Choose between 0 and 300 but in multiples of 50 only

3. Mark how much you will like to send back to the sender if you received $450 \mathrm{M}$ ( i.e. the sender sent you $100 \mathrm{M}$ ). Choose between 0 and 450 but in multiples of 50 only

4. Mark how much you will like to send back to the sender if you received $600 \mathrm{M}$ ( i.e. the sender sent you $200 \mathrm{M}$ ). Choose between 0 and 600 but in multiples of 50 only

5. Mark how much you will like to send back to the sender if you received $750 \mathrm{M}$ ( i.e. the sender sent you $100 \mathrm{M}$ ). Choose between 0 and 300 but in multiples of 50 only 
6. Mark how much you will like to send back to the sender if you received $900 \mathrm{M}$ ( i.e. the sender sent you $300 \mathrm{M}$ ). Choose between 0 and 900 but in multiples of 50 only.

7. Mark how much you will like to send back to the sender if you received $1150 \mathrm{M}$ (i.e. the sender sent you $100 \mathrm{M}$ ). Choose between 0 and 300 but in multiples of 50 only

8. Mark how much you will like to send back to the sender if you received $1200 \mathrm{M}$ ( i.e. the sender sent you $400 \mathrm{M}$ ). Choose between 0 and 1200 but in multiples of 50 only.

Now we will randomly determining your role and determine your earnings. Coin toss for Role determination. Heads := you will be paid for Part 1 and Tails:= you will be paid for Part 2. We will toss once more if you get Part 2 in the first toss in order to determine the roles.

We have come to the end of the experiment. Please fill out the exit survey.

\subsection{Exit Survey}

1. Identity Number

2. Generally speaking, would you say that most people can be trusted or that you need to be very careful in dealing with people? (Code one answer):

(a) Most people can be trusted

(b) Need to be very careful

3. Do you think most people would try to take advantage of you if they got the chance, or would they try to be fair?

(a) Most of the time they would try to be fair

(b) Most of the time they would try to take advantage

4. Would you say that most of the time people try to be helpful, or that they are mostly just looking out for themselves?

(a) Most of the time people are helpful

(b) Most of the time they are just looking out for themselves

5. Suppose you left your wallet with Rs. 500 in the Metro. On a scale of 1 to 10, how much do you think are the chances that you will get it back?

6. How much you trust people from various groups. Could you tell me for each whether you trust people from this group completely, somewhat, not very much or not at all?

(a) Your family

(b) Your neighborhood

(c) People you know personally

(d) People you meet for the first time

(e) People of another religion

(f) People of another caste

(g) People of another nationality 
7. How widespread do you think bribe taking and corruption is in this country?

(a) Almost no Public Officials are engaged in it

(b) A few Public Officials are engaged in it

(c) Most Public Officials are engaged in it

(d) Almost all Public Officials are engaged in it

8. Please mention for each of the following actions whether you think it can always be justified, never be justified, or something in between. 1 : Never justified 10: Justifiable

(a) Claiming government benefits to which you are not entitled

(b) Avoiding a fare on public transport

(c) Cheating on taxes if you have a chance

(d) Someone accepting a bribe in the course of their duties

9. Suppose you win a lottery of Rs.1000. How much of it will you be willing to share with a charity of your choice? (You may mention any amount from 0 to 1000)

10. How do you see yourself: are you generally a person who is fully prepared to take risks or do you try to avoid taking risks? Please tick a box on the scale, where the value 0 means: 'not at all willing to take risks' and the value 10 means: 'very willing to take risks'.

11. How do you see yourself: are you a person who is fully prepared to take risks when it comes to car driving/motorcycle riding etc. or do you try to avoid taking risks? Please tick a box on the scale, where the value 0means: 'not at all willing to take risks' and the value 10 means: 'very willing to take risks'.

12. How do you see yourself: are you a person who is fully prepared to take risks when it comes to financial matters or do you try to avoid taking risks? Please tick a box on the scale, where the value 0means: 'not at all willing to take risks' and the value 10 means: 'very willing to take risks'.

13. How do you see yourself: are you a person who is fully prepared to take risks when it comes to sports or leisure activities or do you try to avoid taking risks? Please tick a box on the scale, where the value 0 means: 'not at all willing to take risks' and the value 10 means: 'very willing to take risks'.

14. How do you see yourself: are you a person who is fully prepared to take risks when it comes to career or do you try to avoid taking risks? Please tick a box on the scale, where the value 0 means: 'not at all willing to take risks' and the value 10 means: 'very willing to take risks'.

15. How do you see yourself: are you a person who is fully prepared to take risks when it comes to health matters or do you try to avoid taking risks?Please tick a box on the scale, where the value 0 means: 'not at all willing to take risks' and the value 10 means: 'very willing to take risks'.

16. A short survey about yourself 
(a) Sex

i. Male

ii. Female

(b) Age

(c) Are you the only child of your parents?

i. Yes

ii. No

(d) Ancestral State

(e) Mother Tongue

(f) Political Identity

(g) Total Gross Family Income

(h) Caste Affiliation

(i) Religous Affiliation

(j) Religiosity - Not Religious (1) ... Strongly Religious (4)

(k) Your secondary level exam score was (in \%)

(1) Your higher secondary level exam score was (in \%)

(m) Your CAT/GMAT score (in percentile)

(n) Were the instructions clear? Please write a line or two.

(o) What strategies did you use?Please write a line or two.

(p) How did you decide on the strategies that you chose? Please write a line or two.

(q) What do you think this experiment was about? Please write a line or two. 


\section{Instructions for Second Experiment (Social Norm Elici- tation)}

\subsection{Introduction (Common for BG and UG)}

You are now taking part in an economic decision making study.

We will give each one of you an identity number. Please do not lose your identity number. This entire study is anonymous. Please donot discuss with your neighbors your neighbors at any point during the study.

We will use identity number for payment. Please raise your hands once you have read the questions.

Please write your participant ID in the space provided above.

On the following pages, you will read descriptions of a series of situations. These descriptions correspond to situations in which a person must make a decision. This description will include several possible choices available to, lets say, Individual A.

After you read the description of the decision, you will be asked to evaluate the different possible choices available to Individual A and to decide, for each of the possible actions, whether taking that action would be "socially appropriate" and "consistent with moral or proper social behavior" or "socially inappropriate" and "inconsistent with moral or proper social behavior." By socially appropriate, we mean behavior that most people agree is the "correct" or "ethical" thing to do. Another way to think about what we mean is that if Individual A were to select a socially inappropriate choice, then someone else might be angry at Individual A for doing so.Social appropriateness rating is on a scale of -3 to +3 where -3 is "very socially inappropriate" and +3 is very socially appropriate.

In each of your responses, we would like you to answer as truthfully as possible, based on your opinions of what constitutes socially appropriate or socially inappropriate behavior.

To give you an idea of how the experiment will proceed, we will go through an example and show you how you will indicate your responses. On the next page you will see an example of a situation.

\section{Example: Situation}

Individual $\mathrm{A}$ is at a local coffee shop near campus. While there, Individual A notices that someone has left a wallet at one of the tables. Individual A must decide what to do.Individual A has four possible choices: take the wallet, ask others nearby if the wallet belongs to them, leave the wallet where it is, or give the wallet to the shop manager. Individual A can choose only one of these four options.

The table below presents a list of the possible choices available to Individual A. For each of the choices, please indicate your rating for the social appropriateness of the action on a scale of -3 to +3. Indicate your response, in the table below.

\begin{tabular}{|c||c|}
\hline Individual A's choice & Your rating \\
\hline \hline Take the wallet & \\
\hline \hline Ask others nearby if the wallet belongs to them & \\
\hline \hline Leave the wallet where it is & \\
\hline \hline Give the wallet to the shop manager & \\
\hline
\end{tabular}

If this were one of the situations for this study, you would consider each of the possible choices above and, for that choice, indicate the extent to which you believe taking that action would be "socially appropriate" and "consistent with moral or proper social behavior" or "socially 
inappropriate" and "inconsistent with moral or proper social behavior". Recall that by socially appropriate we mean behavior that most people agree is the "correct" or "ethical" thing to do.

For example, suppose you thought that taking the wallet was very socially inappropriate, asking others nearby if the wallet belongs to them was somewhat socially appropriate, leaving the wallet where it is was somewhat socially inappropriate, and giving the wallet to the shop manager was very socially appropriate. Then you would indicate your responses as follows:

\begin{tabular}{|c|c|}
\hline Individual A's choice & Your Rating \\
\hline \hline Take the wallet & -3 \\
\hline Ask others nearby if the wallet belongs to them & +1 \\
\hline Leave the wallet where it is & -1 \\
\hline Give the wallet to the shop manager & +3 \\
\hline
\end{tabular}

Are there any questions about this example situation or about how to indicate your responses?

On the following pages, the situations deal with decisions that "Individual A" might have to make. For each situation, you will receive a sheet, with a table on which to indicate your responses.

For each situation, the experimenter will read a description of the situation. You will then indicate whether each possible choice available to Individual A is socially appropriate or socially inappropriate.

At the end of the session today, we will select one of the two situations by a coin toss (Head Situation I and Tail - Situation II). We will then ask you to randomly choose one category from an envelope containing all the categories. Thus, we will select both a situation and category at random. For each situation and category, we will compute the most frequently occurring response from all the responses in the room today. We will pay you Rs. 110 for your participation today. However if you give the same response as that most frequently given by other people in the room, then you will receive an additional R.s 110. This amount will be paid to you, in cash, at the conclusion of the experiment.

For instance, if we were to select the example situation above and the possible choice "Leave the wallet where it is," and if your response had been "somewhat socially inappropriate," i.e rating -1, then you would receive Rs. 110, in addition to the Rs. 110 participation fee, if this was the response selected by most other people in today's session. Otherwise you would receive only participation fee which is Rs. 110.

If you have any questions from this point on, please raise your hand and wait for the experimenter to come to you.

Please wait to turn the page until the experimenter asks you to do so. If you have any questions, please raise your hand and wait for the experimenter.

\subsection{The Situation - Bribery Game}

Take a look at Figure 1 (Figure 2(a)). Citizens and Public Officials play a game where they are seated in two separate rooms but each Citizen is randomly matched to exactly one Public Official. A Citizen is asked to complete a pen and paper task in five minutes. The corresponding matched Public Official grades the task of the Citizen he is matched with and gets a salary of 600 . If the Citizen successfully completes the task she "passes" the test, otherwise not. The Citizen is entitled to a payment of 400 in addition to a base amount of 200 if she successfully completes the task and "passes" but she earns only 200 if she fails. However, even if the Citizen successfully completes the task, the supervisor demands a bribe in order to let the Citizen pass and earn more. In other words whether to let the Citizen pass is entirely his discretion. He may demand a bribe amount of $\{100,200,300,400\}$. He can also choose not to take a bribe. However the Citizen may accept to pay 
a bribe or she may reject it. If she accepts it then she gets $200+400$-bribe amount and the public official gets $600+$ bribe amount. If she rejects it then she gets 200 and the public official gets 600 , only. Let us go through the figure to further clarify.

Rate the action of the public official and citizen on a social appropriateness scale of -3 to +3 as stated above.

Remember you are not being asked report your personal appropriateness rating but social appropriateness rating and you will be paid if your rating matches with the rating of most other people.

Rate the actions of Public Official on a scale of -3 and +3 in the response sheet given to you.

Rate the actions of Public Citizen on a scale of -3 to +3 as stated above.

Remember you will be rewarded if your rating matches with the rating of most other people in the room today.

Figure 1 below gives a visual description of the payoffs.

[Figure 1 referred to Figure 2(a) in the paper.]

\subsubsection{Response Sheet}

Identity Number.

Rate Public Official's decision.

\begin{tabular}{|c|c|c|}
\hline \multicolumn{2}{|c|}{ Total amount that can be extracted as bribe is 400. } & \multirow{2}{*}{ Rating } \\
$\begin{array}{c}\text { Amount Sought by } \\
\text { the Public Official as } \\
\text { bribe }\end{array}$ & $\begin{array}{c}\text { Amount of the } \\
\text { entitlement left with } \\
\text { the Citizen }\end{array}$ & \\
\hline $\begin{array}{c}\text { 0 i.e. Public Official } \\
\text { does not ask for a } \\
\text { bribe }\end{array}$ & 400 & \\
\hline $10-50$ & $390-350$ & \\
\hline $60-100$ & $340-300$ & \\
\hline $110-150$ & $290-250$ & \\
\hline $160-200$ & $240-200$ & \\
\hline $210-250$ & $190-150$ & \\
\hline $260-300$ & $140-100$ & \\
\hline $310-350$ & $90-50$ & \\
\hline $360-390$ & $40-10$ & \\
\hline $\begin{array}{c}300 \text { i.e. Public Official } \\
\text { demands the entire } \\
\text { amount as bribe }\end{array}$ & 0 & \\
\hline
\end{tabular}

Rate the decision of the Citizen 


\begin{tabular}{|c|c|c|}
\hline Total surplus that can be extracted as bribe is 400 & \multirow{2}{*}{ Citizen's response } & \multirow{2}{*}{ Rating } \\
\hline Amount Sought by the Public Official as bribe & & \\
\hline \hline 0 i.e. Public Official does not demand a bribe & - & \\
\hline \multirow{2}{*}{$10-50$} & Accept & \\
\hline \multirow{2}{*}{$60-100$} & Reject & \\
\hline \multirow{2}{*}{$110-150$} & Accept & \\
\cline { 2 - 3 } & Reject & \\
\hline \multirow{2}{*}{$160-200$} & Accept & \\
\hline \multirow{2}{*}{$210-250$} & Reject & \\
\hline \multirow{2}{*}{$260-300$} & Accept & \\
\hline \multirow{2}{*}{$310-350$} & Reject & \\
\hline \multirow{2}{*}{$360-390$} & Reject & \\
\hline & Accept & \\
\hline \multirow{2}{*}{40 Reject } & \\
\hline \multirow{2}{*}{400 i.e. Participant B keeps everything for himself } & Accept & \\
\cline { 2 - 3 } & Reject & \\
\hline & Rccept & \\
\hline
\end{tabular}

\subsection{The Situation - Ultimatum Game}

Take a look at Figure 2 [Figure2(b)]. Participants A and Participants B play a game where they are seated in two separate rooms but each Participant A is randomly matched to exactly one Participant B. A Participant A is asked to complete a pen and paper task in five minutes. The corresponding matched Participant B grades the task of the Participant A he is matched with and gets a salary of 600. If the Participant A successfully completes the task she "passes" the test, otherwise not. If Participant A passes then she takes part in a the next part of the game. Otherwise she earns only 200 and leaves. If she proceeds to the next part of the game then she is eligible for a transfer from Participant B i.e. each participant B has 400 with himself, which he can split between himself and Participant A. He could share any amount $\{100,200,300,400\}$, with P-A or he could share nothing with P-A. P-A in turn could accept or reject the proposed division by P-B. If she rejects the offer then she gets only 200 and P-B gets 600 . If he accepts the offer then P-A gets $200+$ amount P-B shares with him and P-B gets $600+$ share he keeps with himself. Let us go through the figure to further clarify.

Rate the action of Participant B on a scale of -3 and +3 in the response sheet given to you.

Rate the action of Participant A on a scale of -3 to +3 as stated above.

Remember you will be rewarded if your rating matches with the rating of most other people.

Figure 2 below gives a visual description of the payoffs.

[Figure 2 referred to Figure 2(b) in the paper.]

\subsubsection{Response Sheet}

Identity Number. 
Rate Participant B's Decision.

\begin{tabular}{|c|c|c|}
\hline \multicolumn{2}{|c|}{ Total amount to be divided is 400 } & \multirow{2}{*}{ Rating } \\
$\begin{array}{c}\text { The part he proposes } \\
\text { to keep with himself. }\end{array}$ & $\begin{array}{c}\text { Amount of the share } \\
\text { left with Participant } \\
\text { A }\end{array}$ & \\
\hline $\begin{array}{c}\text { 0 i.e. Participant B } \\
\text { does not keep } \\
\text { anything with himself }\end{array}$ & 400 & \\
\hline $10-50$ & $390-350$ & \\
\hline $60-100$ & $340-300$ & \\
\hline $110-150$ & $290-250$ & \\
\hline $160-110$ & $240-110$ & \\
\hline $210-250$ & $190-150$ & \\
\hline $260-300$ & $140-100$ & \\
\hline $310-350$ & $90-50$ & \\
\hline $360-390$ & $40-10$ & \\
\hline $\begin{array}{c}\text { 300 i.e. Participant B } \\
\text { keeps everything for } \\
\text { himself }\end{array}$ & 0 & \\
\hline
\end{tabular}

Rate the action of Participant A

\begin{tabular}{|c|c|c|}
\hline Total amount to be divided is 400 & \multirow{2}{*}{ Participant A's response } & \multirow{2}{*}{ Rating } \\
\hline The part participant B proposes to keep with himself. & & \\
\hline 0 i.e. Participant $\mathrm{B}$ does not keep anything with himself & - & \\
\hline \multirow{2}{*}{$10-50$} & Accept & \\
\hline & Reject & \\
\hline \multirow{2}{*}{$60-100$} & Accept & \\
\hline & Reject & \\
\hline \multirow{2}{*}{$110-150$} & Accept & \\
\hline & Reject & \\
\hline \multirow{2}{*}{$160-110$} & Accept & \\
\hline & Reject & \\
\hline \multirow{2}{*}{$210-250$} & Accept & \\
\hline & Reject & \\
\hline \multirow{2}{*}{$260-300$} & Accept & \\
\hline & Reject & \\
\hline \multirow{2}{*}{$310-350$} & Accept & \\
\hline & Reject & \\
\hline \multirow{2}{*}{$360-390$} & Accept & \\
\hline & Reject & \\
\hline \multirow{2}{*}{400 i.e. Participant B keeps everything for himself } & Accept & \\
\hline & Reject & \\
\hline
\end{tabular}

